Reddy \& Hough 2013: Microstructural evolution of Witwatersrand Pyrite. CMP Manuscript

\title{
Microstructural evolution and trace element mobility in Witwatersrand pyrite
}

\author{
Steven M. Reddy ${ }^{1 *} \&$ Robert M. Hough ${ }^{2}$
}

${ }^{1}$ The Institute for Geoscience Research and ARC COE in Core to Crust Fluid Systems,

Department of Applied Geology, Curtin University of Technology, Perth, WA6845, Australia.

${ }^{2}$ CSIRO Earth Science and Resource Engineering, ARRC, 26 Dick Perry Avenue, Kensington, Perth, WA6151, Australia.

Keywords: microstructure; dislocation creep; geochemistry; pyrite; trace element; EBSD;

Witwatersrand

*Corresponding Author:

Steven M. Reddy (S.Reddy@ curtin.edu.au) 


\section{Abstract}

Microstructural analysis of pyrite from a single sample of Witwatersrand conglomerate indicates a complex deformation history involving components of both plastic and brittle deformation. Internal deformation associated with dislocation creep is heterogeneously developed within grains, shows no systematic relationship to bulk rock strain or the location of grain boundaries and is interpreted to represent an episode of pyrite deformation that predates the incorporation of detrital pyrite grains into the Central Rand conglomerates. In contrast, brittle deformation, manifest by grain fragmentation that transects dislocation-related microstructures, is spatially related to grain contacts and is interpreted to represent postdepositional deformation of the Central Rand conglomerates. Analysis of the low-angle boundaries associated with the early dislocation creep phase of deformation indicates the operation of $\langle 010\rangle\{100\}$ slip systems. However, some orientation boundaries have geometrical characteristics that are not consistent with simple $\langle 010\rangle\{100\}$ deformation. These boundaries may represent the combination of multiple slip systems or the operation of the previously unrecognized $<001>\{120\}$ slip system. These boundaries are associated with order of magnitude enrichments in As, $\mathrm{Ni}$ and $\mathrm{Co}$ that indicate a deformation control on the remobilization of trace elements within pyrite and a potential slip system control on the effectiveness of fast-diffusion pathways. The results confirm the importance of grain-scale elemental remobilization within pyrite prior to their incorporation into the Witwatersrand gold-bearing conglomerates. Since the relationship between gold and pyrite is intimately related to the trace element geochemistry of pyrite, the results have implications for the application of minor element geochemistry to ore deposit formation, suggest a reason for heterogeneous conductivity and localized gold precipitation in natural pyrite and provide a framework for improving mineral processing. 


\section{Introduction}

Pyrite $\left(\mathrm{FeS}_{2}\right)$ is the most abundant metal sulfide in the Earth's crust and is found in a range of geological environments within sedimentary, igneous, and metamorphic rocks. In particular, pyrite is a major phase in sulfide-bearing ore deposits associated with base, ferroalloy and precious metals, most notably gold (Wells and Mullens 1973; Leistel et al. 1998; Simon et al. 1999). Pyrite displays trace element and isotopic compositional variability, which have led to the widespread use of pyrite geochemistry to provide constraints on a range of geological processes; for example, oxygenation of the Earth's atmosphere (Canfield et al. 2000; Bekker et al. 2004), microbial activity in ancient rocks (Schieber 2002) and the syn- to postdeposition fluid history of ore deposits (Craig et al. 1998; Clark et al. 2004). Inclusions trapped within pyrite have been utilized to date the timing of ore forming events (Smith et al. 2001; Kirk et al. 2002). In addition, trace element variations can modify the semi-conducting properties of pyrite, and hence its photovoltaic usage (Lehner et al. 2006), its flotation characteristics during mineral extraction (Abraitis et al. 2004) and the chemical mechanisms of pyrite oxidation, the latter having critical implications for acid mine drainage and mineral processing (Evangelou and Zhang 1995; Lehner et al. 2007).

The widespread use of pyrite in geochemical studies requires a comprehensive understanding of the processes by which its composition may be modified under geological conditions. In this paper, microstructural data, obtained by orientation contrast imaging (OCI) and electron backscatter diffraction (EBSD), are presented from a sample from the Welkom goldfield to establish the microstructural evolution and deformation history of Witwatersrand pyrite grains. Microstructural data are then integrated with trace element maps to characterize the spatial and temporal relationships between different microstructures and trace element 
compositional variations. These observations are then used to place constraints on the relative timing of deformation and its effects on pyrite geochemistry. The trace elements arsenic (As), nickel $(\mathrm{Ni})$ and cobalt $(\mathrm{Co})$ have been targeted because of their known occurrence in Witwatersrand pyrites (Reimold et al. 2004), their close relationship to gold mineralization (Przybyłowicz et al. 1995; Foya et al. 1999) and their role in controlling the semiconductor and oxidation characteristics of pyrite (Lehner et al. 2006; Lehner et al. 2007). The results are utilized to provide a framework for understanding trace element variations in pyrite and highlight potential complexities in the relationship between composition and deformation history.

\section{Geological Background}

The Witwatersrand Basin comprises a sequence of sedimentary rocks that represents the remnants of a larger sedimentary basin that formed over the Kaapvaal craton between $~ 2985-$ 2849 Ma (Kositcin and Krapež 2004). At its base, the Witwatersrand Supergroup both conformably and unconformably overlies volcanic and clastic sedimentary rocks of the 3.07 Ga Dominion Group (Armstrong et al. 1991) and are unconformable on Archaean basement rocks (>3.2Ga) (Poujol et al. 2003) of the Kaapvaal craton. The Witwatersrand Supergroup is overlain by the Ventersdorp Supergroup, which contains a basal conglomerate unit (the Ventersdorp Conglomerate Formation) that has been dated at 2729 Ma (Kositcin et al. 2003).

The stratigraphy of the Witwatersrand Supergroup is well established and comprises the basal West Rand Group and the overlying Central Rand Group (McCarthy 2006). These groups record a transition form early deep marine to non-marine sequences and were deposited within an evolving retro-arc foreland basin system (Burke et al. 1986; Catuneanu 2001). Within this evolving, dynamic framework, the deposition of mudstones, sandstones and localized conglomerates represents a dominance of tectonic controls on sedimentation, upon 
which eustatic sea level changes were superimposed in the more distal, marine parts of the basin (Karpeta and Els 1999). Unconformity surfaces, marked by the presence of fluvial conglomerates in the more proximal parts of the Central Rand Group, contain gold. The Central Rand Group rocks in the Welkom district have been metamorphosed at low greenschist facies conditions $\left(\mathrm{T}<350^{\circ} \mathrm{C}, \mathrm{P} \sim 2 \mathrm{kbar}\right)$ (Phillips and Law 1994).

The occurrence of gold within the Central Rand Group is intimately linked to the presence and origin of pyrite, but the nature of gold mineralization remains controversial. End member models include a detrital or placer origin for gold and pyrite (Mellor 1916; Maclean and Fleet 1989; Fleet 1998; Minter 1999; Kirk et al. 2001; England et al. 2002; Meier et al. 2009) and a hydrothermal or metamorphic origin for gold (Graton 1930; Phillips and Myers 1989; Phillips and Law 1994; Barnicoat et al. 1997; Phillips and Powell 2011). However, a "modified placer" model, involving remobilization of placer gold, is supported by some workers (Robb and Meyer 1991; Robb and Meyer 1995; Frimmel 1997; Frimmel 2005; Schaefer et al. 2010). Despite increasingly compelling arguments for the latter, a consensus amongst the Witwatersrand research community remains elusive (cf. Frimmel 1997; Phillips and Powell 2011).

The studied sample comes from the Welkom goldfield of the Witwatersrand Basin, South Africa, a region where pyrite is intimately involved with extensive gold mineralization. The structural evolution of the Welkom goldfield comprises east-verging thrust faults, synchronous with deposition of the Central Rand Group at 2.9 Ga, NNW-striking normal faults at $\sim 2.7 \mathrm{Ga}$, and the younger developments of folds and thrusts following Transvaal Group deposition at $2.2 \mathrm{Ga}$ (Dankert and Hein 2010 and references therein). 


\title{
Analytical Procedure
}

A thin section was prepared normal to bedding, and polished with progressively finer grades of diamond paste $(9-1 \mu \mathrm{m})$, followed by a further 3 hours of polishing with $0.06 \mu \mathrm{m}$ colloidal silica in $\mathrm{NaOH}$ solution ( $\mathrm{pH} 10)$. OCI and EBSD data were collected using a combination of W-sourced Philips XL30 and Zeiss EVO scanning electron microscopes (SEMs), housed at Curtin University, Perth, Australia. EBSD maps were collected from several pyrite grains and one of these was selected for further chemical analysis. Many other grains were observed with OCI in order to ensure the microstructural observations were representative. SEM and EBSP collection settings are similar to those reported elsewhere (see Table 1 of Reddy et al. 2009). Automatic EBSD mapping was undertaken by collecting and indexing an EBSP from each node of user-defined grids using Oxford Instruments' Channel 5 Flamenco software. Empirically obtained EBSPs from the pyrite were automatically indexed to theoretical (hkl) reflector intensities of the different Kikuchi bands of pyrite using crystallographic data (Brostigen and Kjekshus 1969) in the Channel 5 phase database. For all data, mean angular deviation (MAD), was generally low and MADs greater than $1.3^{\circ}$ were rejected from the analysis.

\begin{abstract}
All EBSD data were noise reduced using a "wildspike" correction and a six-neighbour zero solution extrapolation. The EBSD data from each area was then processed in different ways, using the Channel 5 "Tango" module, to produce a series of maps that show different aspects of the microstructure. Band contrast is a measure of the average intensity of the Kikuchi bands in the electron backscatter pattern (EBSP) relative to the overall intensity and is a measurement of pattern quality that is a fundamental property of the EBSP (Maitland and Sitzman 2007). Band contrast is susceptible to variations in crystallographic orientation, structural integrity, crystal damage and surface topography and is therefore particularly useful
\end{abstract}


for qualitatively delimiting the sample microstructure. During data processing, band contrast maps were therefore used as a background over which orientation and boundary data were superimposed. A variety of different maps can be created from orientation data (see Maitland and Sitzman 2007 for recent summary). Orientation maps were produced using inverse pole figures (IPF) by coloring the map with respect to the alignment of the map X direction with a crystallographic IPF. The Channel 5 'texture' component, in which each pixel is colored for minimum misorientation relative to a user-defined reference orientation (white cross), was also used. Local misorientation maps represent the average misorientation between a diffraction pattern and its immediately adjacent eight neighbors in the mapping grid. This plot emphasizes boundaries across which lattice orientations change and is therefore useful for correlating with geochemical data.

Boundaries showing variable misorientation angles were applied to maps using the Channel 5 'grain boundary' component with different colors being assigned to different magnitudes of misorientation angles. Coloring of the same boundaries to depict the 3D geometry of the associated misorientation axis, relative to a colored stereonet, was done using the Channel 5 'misorientation axis' component.

Crystallographic orientation and misorientation axis data were plotted using Channel 5 "Mambo" software using lower hemisphere, equal area projections. All data are reported with respect to an X-Y coordinate framework that is defined for each map that is also shown in the orientation maps. The cubic crystal symmetry of pyrite means that 24 possible misorientation angle/axes may be calculated between two different crystallographic orientations (Grimmer 1980). In this study, the angle/axis pair corresponding to the minimum misorientation angle was used for analysis. This is justified because the changes in misorientation are progressive 
and can be mapped continuously across the grain. It should be noted that angular errors associated with misorientation axis calculations can be up to $\pm 30^{\circ}$ for $2^{\circ}$ misorientation angles, and will vary with angular resolution of the data (Prior 1999). However, the similar geometry of misorientation axes for a range of misorientation angles and the similarity to the crystallographic dispersion axes indicate that misorientation axes data are geologically meaningful. Graphs showing the relative frequency of misorientation angles were calculated using 1000 random assigned lattice orientations (uncorrelated misorientation angles) using Channel 5 software.

Electron microprobe microanalyses were performed on a Cameca SX50, operating at $35 \mathrm{kV}$ and 450nA. The sample was carbon coated. Maps were generated using a $2 \mu \mathrm{m}$ beam size, 256 x 256 pixels, counting for $320 \mathrm{~ms}$ per pixel. Three maps were run over the same area consecutively and the final maps were generated by digital averaging, which reduces the signal to noise ratio. Arsenic was mapped using both the As $L \alpha$ peak and the As $L \alpha$ background whereas nickel was mapped using the Ni Ka peak. A transect was collected using at $2 \mu \mathrm{m}$ step size with a $1 \mu \mathrm{m}$ beam size to enable better spatial resolution across one of the boundaries. Other operating conditions for these transects were identical to those for mapping.

\section{Sample Characteristics}

The sample is a quartz-dominated, poorly-sorted, clast-supported conglomerate. Quartz clasts range from $100 \mu \mathrm{m}$ to several centimetres and comprise different textural types with subrounded to subangular clasts of both high and low sphericity. Quartz pebbles show a range of internal microstructures including single crystal clasts with undulose extinction, deformation bands, subgrains and recrystallized grains. Such features provide evidence of deformation by dislocation creep and dynamic recrystallization. Within individual quartz 
clasts the microstructural characteristics are consistent, but different grains show variable microstructure types (Fig 2c,d).

Although the larger clasts are almost exclusively quartz, at finer grain size $(<2 \mathrm{~mm})$, pyrite becomes a significant clast type. Pyrite shows a bimodal grain size distribution, with 1-2 mm coarser grains and a finer fraction of $100-200 \mu \mathrm{m}$ grains (Fig 2). The coarse grains comprise several different types including rounded, high sphericity, inclusion-free grains; rounded, low sphericity, inclusion-rich grains; and subangular, low sphericity grains showing bands of inclusions (Fig 2). These different pyrite types are similar to many other descriptions of Witwatersrand pyrite and correspond to "rounded compact pyrite", "framboidal pyrite" and "banded porous pyrite", respectively (e.g. Koglin et al. 2010).

The matrix of the conglomerate comprises fine-grained quartz, pyrite, chlorite, sericite, bitumen, zircon and uranitite. Detailed analyses of matrix components in Witwatersrand conglomerates have been given elsewhere (England et al. 2001; Vollbrecht et al. 2002).

Many of the pyrite grains are fractured. Fractures are commonly intragranular and, less commonly, transgranular (Fig. 2). The intensity of fracturing within individual grains is highly variable, and some grains are intensely fragmented. Most fractures are localized at the sites of impingement between coarse grains (Fig 2e,f) and are commonly filled by quartz, chlorite and sericite.

Atomic number contrast (ANC) imaging of the coarse, rounded pyrite grains fails to show any internal microstructure within the grains (Fig. 3a). No resolvable internal chemical variations associated with either pyrite compositional zoning or mineral inclusions are apparent in ANC images. However, a very thin rim of new pyrite is visible on the edge of one pyrite grain (Fig 3a). In contrast, $\mathrm{OCI}$ shows greyscale differences that indicate crystallographic orientation 
variations within the pyrite crystals (Fig. 3b-f) and a microstructural complexity not apparent by ANC imaging (cf. Fig. 3a \& 3b). This complexity is manifest in a series of coarse $(>100 \mu \mathrm{m})$ crystallographic orientation domains and a finer, polygonal microstructure $(c .20 \mu \mathrm{m})$ that cross cut the boundaries of some of the larger orientation domains (Fig. 3b). In most cases, the orientation microstructure shows no spatial relationship to the grain boundaries, and orientation domains occur throughout the grains (Fig. 3). However, in a couple of examples, thin bands of orientation variations are localized at the grain boundaries (Fig $3 b, c)$. In some cases, the orientation variations in the pyrite are clearly cut by fractures (Fig $3 \mathrm{c}, \mathrm{e}$ ), indicating that the fractures are younger.

Orientation mapping via EBSD can be used to quantify the orientation variations within individual coarse pyrite grains and among fragments of the fractured grains. Orientation mapping confirms that the framboidal pyrites are multigrain aggregates of small, randomly oriented, pyrite grains (Fig. 4a,b). In contrast, individual round compact pyrites are single grains displaying discrete orientation domain boundaries (Fig. 4a). The orientation variations (misorientations) are systematic and related to crystallographic dispersion around a single $<100>$ crystal axis that corresponds to the dominant orientation of low-angle $\left(<10^{\circ}\right)$ misorientation axes calculated from adjacent diffraction patterns (Fig. 4c).

In contrast to intragrain orientation boundaries, orientation variations associated with grain fragmentation are not systematic and show no consistent misorientation axis (Fig. 5, 6). Uncorrelated misorientation angles within fragmented and non-fragmented grains consistently show a larger range for fragmented grains than for those grains that only have low-angle boundaries (Fig 5, 6, 7). In almost all cases, low-angle boundaries are cut by fractures (Fig. 6b) and the sites of impingement of pyrite grains show no evidence for the development of 
low-angle misorientation boundaries (Fig. 5 \& 6). However in one grain (grain 1, Fig. 7), lowangle boundaries are developed at the contact of two grains (Fig 7). In this case, the misorientation angles associated with these boundaries are too small to accurately assess if the misorientation axes correspond to low index, rationale orientations associated with dislocation formation, or small fractures. High spatial resolution EBSD mapping close to fracture walls (data not shown) fails to show any convincing evidence of minute textural variations along the crack walls that could be attributed to the operation of dislocation glide in the early stages of fracture development.

In some cases, pyrite grains show embayed grain boundaries, particularly when in contact with harder" accessory phases (e.g. zircon) (Fig. 8). In these cases there is no change of lattice orientation within the embayed region of the boundary indicating dissolution of the pyrite and deformation by a diffusive mass transfer process. In other pyrite grains within the sample, there is further evidence of minor pyrite dissolution and deformation accommodated by diffusive mass transfer at the grain boundary, specifically at sites of impingement with neighboring grains. However, none of this deformation appears to be associated with significant development of low-angle boundaries. Fine pyrite rims on the edge of some grains (Fig. 3a) may mark the sites of redeposition of removed pyrite.

Compact round pyrite grains show a complex intragrain orientation microstructure. One grain, selected for more detailed microstructural and compositional analysis, and showing no signs of fracture (Fig. 3a,b), records a lattice distortion across the grain, with zones of localized recrystallization along discrete, grain-scale, low-angle boundaries (Fig. 9a,b). Orientation variations within the grain are large $\left(\sim 90^{\circ}\right)$ and are dominated by dispersion of crystallographic axes around a single $\{100\}$ pole (Fig. 9c). Low-angle misorientation axes also coincide with the single $\{100\}$ pole (Fig. 9d). The orientation microstructure observed at 
the edge of the grain in orientation contrast images (Fig. 3b) are not apparent in either the IPF or local misorientation maps (Fig. 9a,b) indicating that they are caused by small lattice orientation variations that are insignificant in terms of the larger orientation variations identified in the grain (Fig. 9).

A detailed analysis of a part of the grain shows a complex microstructure (Fig. 10a) with a substructure of discrete low-angle boundaries that are overprinted by zones of more intense recrystallization that show orientation variations up to $45^{\circ}$ (Fig. 10b, e). The recrystallized zones show irregular boundary orientations that are less discrete than the low-angle boundaries that they overprint. Orientation variations are again dominated by crystallographic dispersion and misorientations $\left(2-15^{\circ}\right)$ around a $\{100\}$ pole (Fig. 10e,f).

A chemical map for As (Fig. 10c) shows that the highest As concentrations correlate with several of the orientation boundaries recognised in the OCI images and EBSD data (Figs. 10a,b). Similar patterns of enrichment of Ni coincide with the same boundaries (Fig 10d). A transect (A-A') shows an order of magnitude increase in As, Ni and Co associated with a specific orientation boundary (k) with a misorientation angle of $\sim 5^{\circ}$ (Fig. 10h). The boundary of enriched As, Ni and Co does not correlate with misorientation angle (Fig. 11a). However, mapping of misorientation axes (Fig. 11b) indicate that this boundary is associated with a different misorientation axis defined by an anomalous set of misorientation axes (shown by the red ellipse in Fig 10f), which do not correspond to any low-index crystal axes but have a range of geometries that spread between two $<210>$ axes (Fig. 10g).

\section{Discussion}

Deformation History of Welkom Pyrite 
The origin of the Witwatersrand pyrites in rocks similar to those described here has received considerable attention (see introduction). The sample studied here shows three different types of pyrite grains that are similar to previously characterized pyrite types in the Witwatersrand Basin: fine-grained pyrite that is found in the matrix, framboidal pyrite, and rounded, high sphericity pyrites that are typically referred to as round, compact grains. The framboidal and compact pyrite have different microstructural features.

Round, compact pyrite grains, such as the ones studied here, have previously been considered to be structurally simple, single detrital grains (Frimmel 1997; England et al. 2002). The OCI images and EBSD data in this study show considerable microstructural complexity and, in contrast to previous studies, the grains show a range of intragrain crystallographic misorientation variations up to $90^{\circ}$ around rational-low index directions. The magnitude of these misorientations indicates significant amounts of crystal-plastic deformation, yet the lowaspect ratio pyrite and quartz grain shapes are not consistent with the rock having undergone high strain deformation.

The orientation boundaries identified in the pyrite grain are systematic in that they are associated with crystallographic dispersions and misorientation axes parallel to a dominant $<100>$ direction. The observed orientation variations are accommodated by discrete low- to high-angle boundaries that indicate the operation of dislocation creep (Boyle et al. 1998; Barrie et al. 2007; Barrie et al. 2009).The patterns of varying crystallographic orientations (Fig. 10b,d,e) can be used to infer the slip systems that were active during the pyrite deformation (Reddy et al. 2007; Barrie et al. 2008). In this case, the microstructural data indicate the formation of tilt boundaries dominated by the operation of edge dislocations, associated with symmetrically equivalent $\langle 100>\{001\}$ slip systems, and the subsequent 
Reddy \& Hough 2013: Microstructural evolution of Witwatersrand Pyrite. CMP Manuscript

migration of these dislocations into tilt walls to reduce internal strain energy. These observations are consistent with the dominance of these slip systems in experimental studies on pyrite (Cox et al. 1981; Graf et al. 1981; Levade et al. 1982; Barrie et al. 2008). Finegrained "new" grains within the core of some of these deformed pyrites (Fig.10b) are interpreted to represent the operation of subgrain rotation recrystallization to produce the high-angle boundaries.

Significantly, the microstructures associated with dislocation creep are well developed throughout the pyrite grains and there is no clear relationship between these microstructures and grain boundaries or between different grains. Combined with the observation that grain shapes indicates low strain within the bulk sample, the dislocation creep microstructures are interpreted to predate the erosion and deposition of the detrital grains. The only exception to this interpretation is found, where small lattice misorientations $\left(<1^{\circ}\right)$ are localised at grain boundaries (Fig 3b,c \& Fig. 13), and these are interpreted to reflect the operation of dislocation glide driven by stresses associated with grain-grain impingement after deposition of the pyrite grains (e.g. Barrie et al. 2009).

In contrast to the round compact grains, large framboidal pyrite grains have higher aspect ratios (ellipticity) and comprise aggregates of smaller ( $20 \mu \mathrm{m}$ diameter) pyrite grains. These smaller grains have random crystallographic orientations and record no significant evidence of intragrain low-angle boundaries associated with the formation and migration of dislocations or fine-grained recrystallization. The framboidal pyrites are microstructurally similar to morphologically disordered framboids that are interpreted to have developed by primary growth (Ohfuji et al. 2005). 
Many of the pyrite grains show intragranular and intergranular brittle fractures that emanate from grain boundaries at the sites of grain impingement. This spatial relationship indicates that fracture development is a response to the indentation of adjacent grains, and in three dimensions fractures are likely to be cone cracks formed at the sites of localized high stress. These fractures therefore postdate the juxtaposition of coarse pyrite grains within the sample. Fractures also cut across and displace low-angle boundaries associated with dislocation creep (Figs. 3, 6). Grain fragmentation associated with localized, intense fracturing results in nonsystematic lattice orientation variations within individual grains.

As well as brittle failure, the local presence of slightly embayed contacts between pyritepyrite grains without localized dislocation creep microstructures, is evidence for a limited amount of pyrite dissolution. Diffusive mass transfer is more apparent in the embayment of pyrite in contact with accessory phases in the matrix (e.g. zircon) (Fig. 8). In most cases, pyrite adjacent to sites of diffusive mass transfer preserves no significant deformation accommodated by the formation and migration of dislocations. Fracture edges also fail to show any evidence of dislocation glide, though microstructures formed by dislocation glide may be present along some grain-grain contacts (Fig 7). The localization of diffusive mass transfer microstructures along impinging grain contacts indicates that deformation by this mechanism took place in situ, that is, after the deposition of the grains.

The microstructural data presented here provide further constraints on the origin of Witwatersrand pyrite and provide some new data regarding their evolution. Firstly, round compact grains comprise recrystallized single grains with a large range in misorientation angles that do not appear consistent with the bulk strain of the sample. Framboidal grains 
have elliptical shapes but show little evidence for internal deformation and have microstructural characteristics consistent with primary growth. In addition, low-angle boundaries associated with dislocation creep (misorientation angles $>2^{\circ}$ ) show no relationship to grain edges and there is no systematic relationship between the internal microstructure of the pyrites and their current positions within the sample (Fig. 12b). These observations are consistent with a detrital origin for the pyrite grains, with crystal plasticity associated with the development of low-angle boundaries and subgrain rotation recrystallization in rounded pyrite taking place prior to the erosion, transport and deposition of these pyrites in a placer environment. The different pyrite clast types are interpreted to represent multiple sources for pyrite detritus, a similar conclusion to that derived from the analysis of Witwatersrand quartz clasts (Vollbrecht et al. 2002).

In contrast to the characteristics of dislocation creep microstructures, deformation in the form of fracture and grain fragmentation, is systematic in being associated with the impingement of neighbor grains (Fig 12b), and clearly post-dates deposition of the grains and formation of the conglomerate. This deformation is likely to have initiated during the early stages of sedimentary compaction. However, evidence for diffusive mass transfer and dislocation glide processes, plus the presence of chlorite and sericite in some of these fractures, indicates that deformation probably continued to over a prolonged part of the burial history.

The microstructural data therefore indicates a two-stage deformation history, manifest by the operation of different deformation mechanisms, that took place prior to, and after, deposition of the Central Rand group sediments. 
Experimental and empirical evidence indicates that pyrite deforms by a range of processes at natural strain rates within the Earth's crust (Atkinson 1975; Cox et al. 1981; Graf et al. 1981; McClay and Ellis 1983; Boyle et al. 1998; Freitag et al. 2004; Barrie et al. 2009). Experimental work indicates the operation of the dislocation creep field for pyrite deformation at higher temperatures than expected for fracture and diffusive mass transfer (McClay and Ellis 1983). However, recent detailed microstructural studies on experimental and natural pyrites indicate the development of localized dislocation creep microstructures may arise at lower temperature conditions (Fig 12a) (Barrie et al. 2009). Despite these observations, the distinct characteristics of the two-stage deformation history in the Central Rand sample point to a higher-temperature deformation event being responsible for the early development of dislocation creep microstructures in the round compact pyrites.

\section{Relationship between Deformation, Microstructure and Compositional Variation}

Microstructures (dislocations and low-angle boundaries) formed by plastic deformation are known to have a dramatic effect on the diffusion properties of minerals by forming fastdiffusion pathways that facilitate the chemical modification of minerals at much greater rates than volume diffusion (e.g. Lee 1995; Reddy et al. 2006; Timms et al. 2011). However, the role that even small amounts of deformation play in facilitating chemical mobility in pyrite is poorly known. The quantitative microstructural and geochemical data presented here demonstrate a systematic relationship between trace element enrichment and pyrite deformation.

There are several possible explanations as to why specific orientation boundaries are enriched. The boundary enriched with $\mathrm{As}, \mathrm{Ni}$, and $\mathrm{Co}$ has a $<5^{\circ}$ misorientation angle, a value comparable to other orientation boundaries in the sample that do not show enrichment (Fig. 
11). Therefore, chemical enrichment does not correspond to the magnitude of boundary misorientation angle. A further possibility is that the different enriched low-angle boundary developed prior to low-angle boundaries associated with $<001>\{100\}$ slip and during differing chemical conditions. Such an interpretation is allowed by the cross cutting nature of the different microstructures (Fig. 10a,b). However, $<001>\{100\}$ slip dominates dislocation creep in pyrite and it is therefore expected that tilt boundaries associated with $<001>\{100\}$ slip would also dominate any earlier deformation associated with the formation of the enriched boundary and would therefore also be chemically modified. There is no evidence of this.

In detail, the enriched boundary $(\mathrm{k})$ is segmented with each segment recording a different orientation of the boundary trace and associated misorientation axes that define a trend between two $\{210\}$ poles (Fig. 10g). The geometry of the trace segments and associated misorientation axes (Fig. 10g) is not consistent with $<001>\{100\}$ slip or any simple tilt or twist boundary model associated with any known pyrite slip systems. One possible interpretation is that the boundary represents the activity of multiple slip systems at a scale that is unresolvable in the current data. Different boundary segments may then represent differing degrees of slip system activity. These slip systems may represent various contributions from $<001>\{100\}$. However, the proximity of misorientation axes to $\langle 210>$ may point towards the operation of previously unrecognized $<001>\{120\}$. This slip system has not previously been recorded in pyrite. However, this may reflect the fact that most studies of pyrite deformation have used either a multigrain fabric approach to infer slip systems (Cox et al. 1981; Siemes et al. 1993) or have analysed the geometry of individual dislocations using the transmission electron microscope (Cox et al. 1981; Graf et al. 1981; Levade et al. 1982). In both cases, the approach tends to recognize the dominant slip system 
and is unlikely to lead to the recognition of less common ones. Despite the inability of current data to fully resolve the microstructural nature of the enriched boundary, it appears that the enrichment in As, Ni and Co takes place along orientation domain boundaries that are complex and different from the ubiquitous boundaries associated with $<001>\{100\}$ slip systems. The variation in As, Ni and Co is therefore inferred to represent a slip system control on element mobility, such that the complex interaction of different slip planes, with different lattice spacings and Burgers vectors, facilitate the diffusion of different species at faster rates than volume diffusion alone.

In Witwatersrand gold deposits, the occurrence of authigenic cobaltite (CoAsS) and gersdorffite (NiAsS) (Frimmel et al. 1993) indicate post-depositional As, Ni and Co migration within the rock matrix. However, the enrichment of $\mathrm{As}$, $\mathrm{Ni}$ and $\mathrm{Co}$ within the studied pyrite is interpreted to be related to crystal plasticity that took place within the source region of compact pyrite prior to its erosion and redeposition in the Central Rand group placer deposits. Given the relationship between Au and As, the data presented here indicate the possibility of gold mobilization and redistribution prior to Central Rand Group deposition by enhanced diffusion of these elements from the matrix into the pyrite along specific low-angle boundaries that behaved as fast-diffusion pathways during an early, high-temperature $\left(>500^{\circ} \mathrm{C}\right)$ deformation event. The microstructural and trace element data are therefore consistent with mobilization of gold both prior to, and after, redeposition of eroded pyrite clasts into the Central Rand sediments. Such features may explain some of the controversies between placer and hydrothermal models for Witwatersrand gold mineralization and are consistent with recent models for remobilization of gold in modified placer models (Robb and Meyer 1991; Robb and Meyer 1995; Frimmel 1997; Frimmel 2005; Schaefer et al. 2010). 
In many deposits, it is common for gold to be intimately associated with pyrite as "invisible gold" (Maddox et al. 1998). The nature of the relationship is complex and may be in the form of a solid solution with the pyrite (Reich et al. 2005), or discrete, structurally-bound nanoparticles (Palenik et al. 2004). These end-member possibilities have been shown to reflect the amount of As in the pyrite (Reich et al. 2005) and have been linked to the electrochemical precipitation of gold at low / high As boundaries (Belcher et al. 2004). The positive correlation between gold and As has been documented in the Witwatersrand gold deposits and has been interpreted to be a result of mixed conductivity and electron exchange along chemical (As) contrast boundaries (Meyer et al. 1990; Przybyłowicz et al. 1995). Consequently, the development of zones of localized As, Ni and Co enrichment, and the likely associated increase in localized conductivity, provides a mechanism of producing chemical boundaries that facilitate heterogeneous gold precipitation at the intragrain scale. The mobilization of As, combined with a knowledge that gold and As are linked, provides further indirect support for syn-deformational remobilization of gold rather than a solely placer origin for Witwatersrand gold mineralization. As well as controlling whether gold is chemically alloyed with pyrite or exists as discrete nano-particles, trace element enriched zones will also localize changes in pyrite reactivity and oxidation (Evangelou and Zhang 1995; Lehner et al. 2007). The microstructural development of pyrite will therefore also dictate the nature of pyrite breakdown reactions, critical to the optimization of ore processing techniques and gold recovery. However, further characterization of the range of conditions of natural pyrite deformation mechanisms are needed if the enrichment of $\mathrm{As}, \mathrm{Ni}$ and $\mathrm{Co}$ is to be utilized in gold recovery processing. 
The intimate nature of pyrite and gold has allowed many researchers to obtain information on ore deposit fluid chemistry and the timing of gold mineralization through the analysis of sulfur and argon isotopes (Smith et al. 2001; Clark et al. 2004). Such studies require that pyrite remain a closed system for isotopic diffusion. However, the development of deformation-related orientation boundaries, which facilitate fast-path diffusion, indicates that the closed system assumption may not be valid. In many pyrite geochemical studies anomalous single point analysis are often attributed to the presence of discrete mineral inclusions. Our study however, shows that anomalous element concentrations can also be directly related to deformation microstructures.

As the most common sulfide on Earth, pyrite is often considered an excellent record of host rock history, even where it has undergone high pressures and temperatures and from geological environments as wide ranging as mantle xenolith sulfide inclusions, ore deposits, early earth deposits and modern sediments. The combined microstructural and microchemical approach outlined here reveals a new level of complexity that requires greater consideration of microstructural characteristics in pyrite geochemical studies and precludes the assumption of chemical mobility simply by volume diffusion. This finding has the potential to develop new analytical approaches for constraining geological processes associated with ore body evolution, and their distal footprints, and the further development and optimization of the industrial applications of pyrite.

\section{Acknowledgements}

Neil Phillips is thanked for provision of the sample. The CSIRO Minerals Down Under National Research Flagship and Science and Innovation Endowment Fund are thanked for funding support. Nick Timms, Alan Boyle and Stephen Cox are thanked for providing 
valuable comments on an earlier draft of this manuscript. Craig Barrie and anonymous reviewer are thanked for their comments of this version of the manuscript. This is TIGeR publication XXX and ARC CCFS COE publication YYY.

\section{References}

Abraitis PK, Pattrick RAD, Vaughan DJ (2004) Variations in the compositional, textural and electrical properties of natural pyrite: a review. Int J Miner Processing 74:41-59.

Armstrong RA, Compston W, Retief EA, Williams, IS, Welke, HJ (1991) Zircon ion microprobe studies bearing on the age and evolution of the Witwatersrand triad. Precambrian Res 53:243-266.

Atkinson BK (1975) Experimental deformation of polycrystalline pyrite; effects of temperature, confining pressure, strain rate, and porosity. Econ Geol 70:473-487.

Barnicoat AC, Henderson IHC, Knipe RJ, Yardley BWD, Napier RW, Fox NPC, Kenyon AK, Muntigh DJ, Strydon D, Winkler KS, Lawrence SR, Cornford C (1997) Hydrothermal gold mineralization in the Witwatersrand basin. Nature 386:820-824.

Barrie CD, Boyle AP, Cox SF, Prior DJ (2008) Slip systems and critical resolved shear stress in pyrite: an electron backscatter diffraction (EBSD) investigation. Mineral Mag 72:1181-1199.

Barrie CD, Boyle AP, Prior DJ (2007) An analysis of the microstructures developed in experimentally deformed polycrystalline pyrite and minor sulphide phases using electron backscatter diffraction. J Struct Geol 29:1494-1511.

Barrie CD, Boyle AP, Salter M (2009) How low can you go?-Extending downwards the limits of plastic deformation in pyrite. Mineral Mag 73:895-913.

Bekker A, Holland HD, Wang PL, Rumble III D, Stein HJ, Hannah JL, Coetzee LL, Beukes NJ (2004) Dating the rise of atmospheric oxygen. Nature 427:117-120.

Belcher RW, Rozendaal A, Przybylowicz WJ (2004) Trace element zoning in pyrite determined by PIXE elemental mapping: evidence for varying ore-fluid composition and electrochemical precipitation of gold at the Spitskop deposit, Saldania Belt, South Africa. 33:174-180.

Boyle AP, Prior DJ, Banham MH, Timms NE (1998) Plastic deformation of metamorphic pyrite: New evidence from electron-backscatter diffraction and forescatter orientationcontrast imaging. Miner Deposita 34:71-81.

Brostigen G, Kjekshus A (1969) Redetermined crystal structure of FeS 2 (pyrite). Acta Chem Scand 23:2186-2188.

Burke K, Kidd W, Kusky TM (1986) Archean foreland basin tectonics in the Witwatersrand, South Africa. Tectonics 5:439-456. 
Canfield DE, Habicht KS, Thamdrup B (2000) The Archean sulfur cycle and the early history of atmospheric oxygen. Science 288:658-661.

Catuneanu O (2001) Flexural partitioning of the Late Archaean Witwatersrand foreland system, South Africa. Sediment Geol 141-142:95-112.

Clark C, Grguric B, Mumm A (2004) Genetic implications of pyrite chemistry from the Palaeoproterozoic Olary Domain and overlying Neoproterozoic Adelaidean sequences, northeastern South Australia. Ore Geol Rev 25:237-257.

Cox SF, Etheridge MA, Hobbs BE (1981) The experimental ductile deformation of polycrystalline and single crystal pyrite. Econ Geol 76:2105-2117.

Craig JR, Vokes FM, Solberg TN (1998) Pyrite: Physical and chemical textures. Miner Deposita 34:82-101.

Dankert BT, Hein KAA (2010) Evaluating the structural character and tectonic history of the Witwatersrand Basin. Precambrian Res 177:1-22.

England GL, Rasmussen B, Krapez B, Groves DI (2002) Palaeoenvironmental significance of rounded pyrite in siliciclastic sequences of the Late Archaean Witwatersrand Basin: Oxygen-deficient atmosphere or hydrothermal alteration? Sedimentology 49:1133-1156.

England GL, Rasmussen B, Krapez B, Groves DI (2001) The origin of uraninite, bitumen nodules, and carbon seams in Witwatersrand gold-uranium-pyrite ore deposits, based on a permo-triassic analogue. Econ Geol Bull Soc 96:1907-1920.

Evangelou VP, Zhang YL (1995) A review: Pyrite oxidation mechanisms and acid mine drainage prevention. Crit Rev Env Sci Tec 25:141-199.

Fleet ME (1998) Detrital pyrite in Witwatersrand gold reefs: X-ray diffraction evidence and implications for atmospheric evolution. Terra Nova 10:302-306.

Foya SN, Reimold WU, Przybylowicz WJ, Gibson RL (1999) PIXE microanalysis of goldpyrite associations from the Kimberley Reefs, Witwatersrand basin, South Africa. Nucl Instrum Meth B 158:588-592.

Freitag K, Boyle AP, Nelson E, Hitzman M, Churchill J, Lopez-Pedrosa M (2004) The use of electron backscatter diffraction and orientation contrast imaging as tools for sulphide textural studies: Example from the Greens Creek deposit (Alaska). Miner Deposita 39:103-113.

Frimmel HE (1997) Detrital origin of hydrothermal Witwatersrand gold - A review. Terra Nova 9:192-197.

Frimmel HE (2005) Archaean atmospheric evolution: evidence from the Witwatersrand gold fields, South Africa. Earth-Sci Rev 70:1-46.

Frimmel HE, Le Roex AP, Knight J, Minter WEL (1993) A case study of the postdepositional alteration of the Witwatersrand Basal Reef gold placer. Econ Geol 88:249265. 
Graf JL, Skinner BJ, Bras J, Fagot M, Levade C, Couderc JJ (1981) Transmission ElectronMicroscopic Observation of Plastic-Deformation in Experimentally Deformed Pyrite. Econ Geol 76:738-742.

Graton CL (1930) Hydrothermal origin of the Rand gold deposits; Part 1, Testimony of the conglomerates. Econ Geol 25:1-185.

Grimmer H (1980) A unique description of the relative orientation of neighbouring grains. Acta Crystal A-Crys 36:382-389.

Karpeta WP, Els BG (1999) The auriferous late Archaean Central Rand Group of South Africa: Sea-level control of sedimentation? Precambrian Res 97:191-214.

Kirk J, Ruiz J, Chesley J, Titley s, Wlashe J (2001) A detrital model for the origin of gold and sulfides in the Witwatersrand basin based on Re-Os isotopes. Geochim Cosmochim Acta 65:2149-2159.

Kirk J, Ruiz J, Chesley J, (2002) A major Archean, gold- and crust-forming event in the Kaapvaal Craton, South Africa. Science 297:1856-1858.

Koglin N, Zeh A, Frimmel HE, Gerdes A (2010) New constraints on the auriferous Witwatersrand sediment provenance from combined detrital zircon U-Pb and Lu-Hf isotope data for the Eldorado Reef (Central Rand Group, South Africa). Precambrian Res 183:817-824.

Kositcin N, Krapež B (2004) Relationship between detrital zircon age-spectra and the tectonic evolution of the Late Archaean Witwatersrand Basin, South Africa. Precambrian Res 129:141-168.

Kositcin N, McNaughton NJ, Griffin BJ, Fletcher, I.R., Groves, D.I. Rasmussen, B.et al. (2003) Textural and geochemical discrimination between xenotime of different origin in the Archaean Witwatersrand Basin, South Africa. Geochim Cosmochim Acta 67:709_ 731.

Lee JKW (1995) Multipath diffusion in geochronology. Contrib Mineral Petr 120:60-82.

Lehner S, Savage K, Ciobanu M, Cliffel DE (2007) The effect of As, Co, and Ni impurities on pyrite oxidation kinetics: An electrochemical study of synthetic pyrite. Geochim Cosmochim Acta 71:2491-2509.

Lehner SW, Savage KS, Ayers JC (2006) Vapor growth and characterization of pyrite (FeS2) doped with $\mathrm{Co}, \mathrm{Ni}$, and As: Variations in semiconducting properties. J Cryst Growth 286:306-317.

Leistel JM, Marcoux E, Thiéblemont D, Quesada C, Sânchez A, Almódovar GR, Pascual E, Sáez R (1998) The volcanic-hosted massive sulphide deposits of the Iberian Pyrite Belt: Review and preface to the Thematic Issue. Miner Deposita 33:2-30.

Levade C, Couderc JJ, Bras J, Fagot M (1982) Transmission electron microscopy study of experimentally deformed pyrite. 46:307-325. 
Maclean PJ, Fleet ME (1989) Detrital pyrite in the Witwatersrand gold fields of South Africa: evidence from truncated growth banding. Econ Geol 84:2008-2011.

Maddox LM, Bancroft GM, Scaini MJ, Lorimer JW (1998) Invisible gold; comparison of Au deposition on pyrite and arsenopyrite. Am Mineral 83:1240-1245.

Maitland T, Sitzman S (2007) Electron backscatter diffraction (EBSD) technique and materials characterization examples. In: Zhou W, Wang ZL (eds) Scanning Microscopy for Nanotechnology: Techniques and Applications. Springer. 41-75pp.

McCarthy TS (2006) The Witwatersrand Supergroup. In: Johnson MR, Anhaeusser CR Thomas RJ (eds) The Geology of South Africa. Geological Society of South Africa, johannesburg/Council for Geoscience, Pretoria, 155-186 pp.

McClay KR, Ellis PG (1983) Deformation and recrystallization of pyrite. Mineral Mag 47:527-538.

Meier DL, Heinrich CA, Watts MA (2009) Mafic dikes displacing Witwatersrand gold reefs: Evidence against metamorphic-hydrothermal ore formation. Geol 37:607-610.

Mellor ET (1916) The conglomerates of the Witwatersrand. T I Min Metall B 25:226-348.

Meyer FM, Robb LJ, Oberthur T, Saager R, Stupp HD (1990) Cobalt, nickel, and gold in pyrite from primary gold deposits and Witwatersrand reefs. S Afr J Geol 93:70-82.

Minter WEL (1999) Irrefutable detrital origin of Witwatersrand gold and evidence of Eolian signatures. Econ Geol Bull Soc 94:665-670.

Ohfuji H, Boyle AP, Prior DJ, Rickard D (2005) Structure of framboidal pyrite: An electron backscatter diffraction study. Am Mineral 90:1693-1704.

Palenik CS, Utsunomiya S, Reich M, et al. (2004) "Invisible" gold revealed: Direct imaging of gold nanoparticles in a Carlin-type deposit. Am Mineral 89:1359-1366.

Phillips NG, Law JDM (1994) Metamorphism of the Witwatersrand gold fields: A review. Ore Geol Rev 9:1-31.

Phillips NG, Myers RE (1989) The Witwatersrand gold fields: Part II. An origin for Witwatersrand gold during metamorphism and associated alteration. Economic Geology Monograph 6:598-608.

Phillips NG, Powell R (2011) Origin of Witwatersrand gold: a metamorphic devolatilisation-hydrothermal replacement model. Applied Earth Science (T I Min Metall B) 120:112-129.

Poujol M, Robb LJ, Anhaeusser CR, Gericke B (2003) A review of the geochronological constraints on the evolution of the Kaapvaal Craton, South Africa. Precambrian Res 127:181-213.

Prior DJ (1999) Problems in determining the misorientation axes, for small angular misorientations, using electron backscatter diffraction in the SEM. J Microscopy 
$195: 217-225$.

Przybyłowicz WJ, Prozesky VM, Meyer FM (1995) True elemental imaging of pyrites from Witwatersrand reefs. Nuclear Inst and Methods in Physics Research, B 104:450-455.

Rasmussen B, Muhling JR (2009) Reactions destroying detrital monazite in greenschist-facies sandstones from the Witwatersrand basin, South Africa. Chem Geol 264:311-327.

Reddy SM, Timms NE, Hamilton PJ, Smyth HR (2009) Deformation-related microstructures in magmatic zircon and implications for diffusion. Contrib Mineral Petr 157:231-244.

Reddy SM, Timms NE, Pantleon W, Trimby P (2007) Quantitative characterization of plastic deformation of zircon and geological implications. Contrib Mineral Petr 153:625-645.

Reddy SM, Timms NE, Trimby P, Kinny PD, Buchan C, Blake K (2006) Crystal-plastic deformation of zircon: A defect in the assumption of chemical robustness. Geol 34:257260.

Reich M, Kesler SE, Utsunomiya S, Palenik CS, Chryssoulis SL, Ewing, RC (2005) Solubility of gold in arsenian pyrite. 69:2781-2796.

Reimold WU, Przybylowicz WJ, Gibson RL (2004) Quantitative major and trace elemental mapping by PIXE of concretionary pyrite from the Witwatersrand Basin, South Africa. X-Ray Spectrom 33:189-203.

Robb LJ, Meyer FM (1991) A contribution to recent debate concerning epigenetic versus syngenetic mineralization processes in the Witwatersrand basin. Econ Geol 86:396-401.

Robb LJ, Meyer FM (1995) The Witwatersrand Basin, South Africa: Geological framework and mineralization processes. Ore Geol Rev 10:67-94.

Schaefer B, Pearson D, Rogers N, Barnicoat A (2010) Re-Os isotope and PGE constraints on the timing and origin of gold mineralisation in the Witwatersrand Basin. Chem Geol 276:88-94.

Schieber J (2002) Sedimentary pyrite: A window into the microbial past. Geol 30:531-534.

Siemes H, Zilles D, Cox SF, Merz P, Schäfer W, Will G, Schaeben H, Kunze K (1993) Preferred orientation of experimentally deformed pyrite measured by means of neutron diffraction. Mineral Mag 57:29-43.

Simon G, Kesler SE, Chryssoulis S (1999) Geochemistry and textures of gold-bearing arsenian pyrite, Twin Creeks, Nevada: Implications for deposition of gold in Carlin-type deposits. Econ Geol 94:405-421.

Smith PE, Evensen NM, York D, Szatmari P, Custodio de Oliveira D (2001) Single-crystal 40Ar-39Ar dating of pyrite: No fool's clock. Geol 29:403-406.

Timms NE, Kinny PD, Reddy SM, Evans K, Clark C, Healy D (2011) Relationship among titanium, rare earth elements, $\mathrm{U}-\mathrm{Pb}$ ages and deformation microstructures in zircon: Implications for Ti-in-zircon thermometry. Chem Geol 280:33-46. 
Reddy \& Hough 2013: Microstructural evolution of Witwatersrand Pyrite. CMP Manuscript

Vollbrecht A, Oberthür T, Ruedrich J, Weber K (2002) Microfabric analyses applied to the Witwatersrand gold- and uranium-bearing conglomerates: constraints on the provenance and post-depositional modification of rock and ore components. Miner Deposita 37:433451.

Wells JD, Mullens TE (1973) Gold-bearing arsenian pyrite determined by microprobe analysis, Cortez and Carlin gold mines, Nevada. Econ Geol 68:187-201. 


\section{Figure Captions}

Figure 1. Simplified geological map of the Witwatersrand region showing the distribution of major sedimentary groups and goldfields. Figure modified from Rasmussen \& Muhling (2009).

Figure 2. Photomicrographs of the studied thin section. Yellow rectangles represent the locality of reflected light photomicrographs (Fig 2d-f) and orientation maps (Figs 4-8). Labeled grains correspond to grains shown in Fig. 3. a) reflected light, image showing distribution of pyrite (white) and quartz (grey). b \& c) plane polarized and cross polarized (with sensitive tint plate) images, respectively, showing grain size and microstructural variations in quartz. Colour variations show the presence of subgrains and deformation bands. d) reflected light image showing variations in round compact pyrite, framboidal pyrite and finer grained pyrite. $d \&$ e) relationship between pyrite grains and fractures. Fracture density is variable amongst grains and fractures tend to nucleate at the grain contacts.

Figure 3. Scanning electron microscopy images of pyrite grains identified in Fig. 2. a) Atomic number contrast image of round compact pyrite shown in $2 \mathrm{~d}$. The homogenous greyscale contrasts the orientation contrast image (b). b-f) Orientation contrast images showing lattice orientation variations in five round compact pyrite grains. b) Patchy greyscale variations throughout the grain appear overprinted by zones of finer-grained recrystallized pyrite. On the left hand margin of the grain, the striped appearance indicates a localized zone of lattice distortion on the grain margin. A similar pattern is seen along the right hand margin of the pyrite grain in (c). d-f show lattice orientation variations are present throughout the whole grain. However, in all cases the greyscale variations are only qualitatitive and cannot be used to constrain the amount of lattice distortion. 
Figure 4. Euler orientation map (a) showing microstructure in framboidal and large compact pyrite grains. Colour differences represent different lattice orientations in pyrite and correspond to the colours shown in the $\{100\}$ pole figures (b \& c). Red lines represent lowangle boundaries with misorientation angles between $2-10^{\circ}$. Projections show the orientation of $\{100\}$ poles and $2-5^{\circ}$ misorientation axes. Framboidal pyrite comprises a large number of small grains ( $\sim 20 \mu \mathrm{m}$ grains) that have random orientations (b). The compact grain comprises a single crystal that has a systematically changing lattice orientation (c) associated with misorientation axes that lie parallel to one of the $\{100\}$ poles.

Figure 5. a) Band contrast and b) IPF maps of compact rounded pyrites. c) pole figures for $\{100\},\{110\}$ and $\{111\}$ for grains $1,2 \& 3$ (top, middle \& bottom respectively). Colors in the map correlate with those in the pole figures. d) Misorientation angle distribution, calculated from 1000 uncorrelated orientations per grain, for grains 1 (blue), 2 (red) and 3 (green). The theoretical random distribution is shown by the black line. $n$ is the number of EBSPs (in thousands) used to construct each grain.

Figure 6. a) Band contrast and b) IPF maps of an intensely fractured rounded pyrite. Map was created from a $560 \times 350$ grid at $2.5 \mu \mathrm{m}$ step size ( 97,000 EBSPs). b) low-angle boundaries that can be traced across the different fragments. c) misorientation angle distribution, calculated from 1000 uncorrelated orientations per grain. The theoretical random distribution is shown by the black line. d) pole figures for $\{100\},\{110\}$ and $\{111\}$. Colors in the IPF map correlate with colors in the pole figures. 
Figure 7. Euler orientation maps to show microstructural relationships in round compact pyrite grains. b) shows detail of area shown in the white square of (a). c) Pole figure orientations for the green / red grain at the top (grain 1) and the blue grain in the middle of the map (grain 2). The fractured grain shows a more dispersed and less systematic range of orientations than grain 1 .

Figure 8. EBSD orientation map showing deformation around a small zircon grain. Colours show Euler orientations of pyrite grains and different colours represent different orientations. Greyscale variations show band contrast variations in non-pyrite phases. The fractured grain in the centre of the image is zircon. The embayed boundaries at sites of impingement (marked DMT) indicate deformation by a diffusive mass transfer process. Orientations variations in the purple pyrite grain are $<1^{\circ}$.

Figure 9. IPF (a) and local misorientation (b) maps of the rounded compact pyrite shown in Fig 3a. Maps were created using a 400 x 450 grid and $6 \mu \mathrm{m}$ step size. Lattice orientations vary significantly associated with dispersion (c) and misorientation axes (d) dominated by a single $<100>$ direction. Note that the orientation variations localized at the grain margin in the orientation contrast image (Fig. 3b) are not seen in the IPF map, indicating that the lattice orientation variations associated with these microstructures are small.

Figure 10. Pyrite microanalytical data from area shown in Fig. 9. a) Detailed orientation contrast image of pyrite microstructure. White box shows location of b, c and d; A-A' indicates orientation of profile shown in (h); b) Orientation map of pyrite comprising 33,000 individual EBSD determinations. Color corresponds to a misorientation from reference point (white cross) from blue $\left(0^{\circ}\right)$ to red $\left(45^{\circ}\right)$. Sharp changes correspond to orientation boundaries 
associated with dislocation migration (e.g. boundary k). c) and d) Abundance of arsenic (c) and Nickel (d) within the pyrite. Note the heterogeneous enrichment (lighter areas) in both As and Ni that correlates exactly with some orientation boundaries (k). e) Pole figures of crystallographic orientation variations shown by colors in b. f) Geometry of misorientation axis / angle pairs shown for $2-4^{\circ}, 4-6^{\circ}$ and $6-15^{\circ}$ misorientation angles. The majority of data correspond to axis of rotation (r) shown in (e). Dispersion of crystallographic axes around the single $\langle 100\rangle$ direction can be related to the operation of two $<010>(100)$ slip systems during deformation. The red ring corresponds to data associated with boundary k shown in detail in (g). g) Projection of misorientation axes and the boundary traces for different segments (k1k4) of boundary k. The three great circles correspond to $\{100\}$ planes. h) Variation in trace element abundance (As, $\mathrm{Ni}, \mathrm{Co}$ ), and corresponding variations in misorientation angle along profile A-A' in (a). The increase in As, Ni, and Co correlates with boundary k. Orientation variations associated with crystallographic dispersion around $<001>$ and $<001\rangle$ misorientation axes show no significant enrichment.

Figure 11. EBSD orientation maps showing boundary characteristics for area shown in Fig 9b draped over a greyscale band contrast map. The ' $k$ ' marks the boundary shown in Fig. 9. a) Misorientation angle distributions in the boundary network. b) shows the orientation of misorientation axes with respect to the inset projection. The boundary $\mathrm{k}$ differs from the majority of other blue boundaries and this reflects the variation of misorientation axes shown in Fig. 9e.

Figure 12. Schematic summary of deformation mechanisms in deformed pyrite a) after Barrie et al (2009) and b) for the grains shown in Fig. 2a. The red grains in b) are round compact pyrites that are similar to those shown in yellow. However, the red depicts grains that have 
Reddy \& Hough 2013: Microstructural evolution of Witwatersrand Pyrite. CMP Manuscript

been studied by OCI (Fig. 3) or EBSD (Figs. 4-9) and show evidence for dislocation creep and subgrain rotation recrystallization. Black lines cutting across grains in b) represent fractures. Orange represents zones where diffusive mass transfer (DMT) processes are inferred from the convex-concave shapes of grain-grain contacts. The matrix comprises finegrained quartz and pyrite with minor bitumen, chlorite, sericite and zircon f. pyrite = framboidal pyrite; rc pyrite $=$ round compact pyrite . 


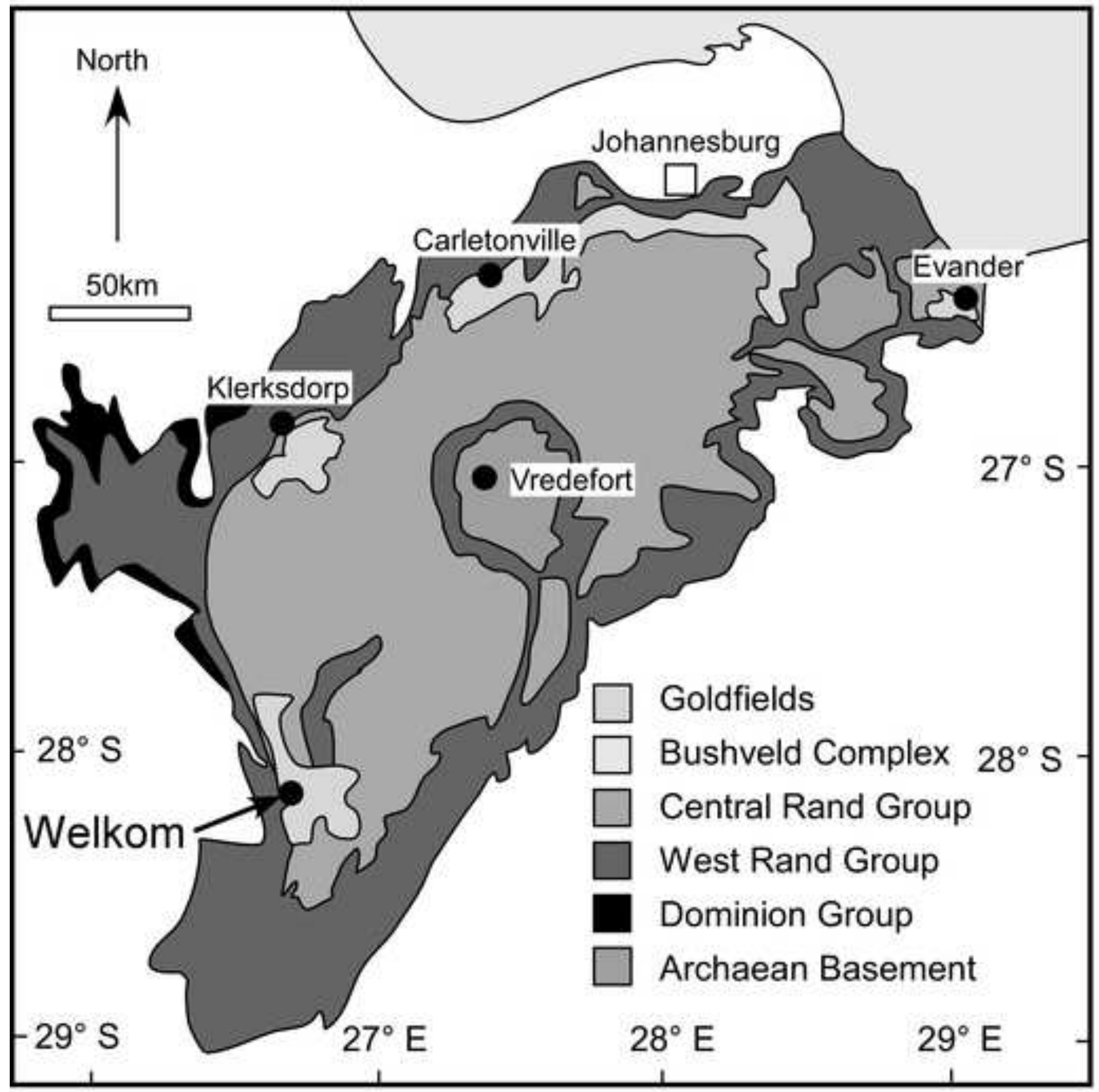

Reddy \& Hough 2012. Fig. 1

recommended width $=84 \mathrm{~mm}$ 

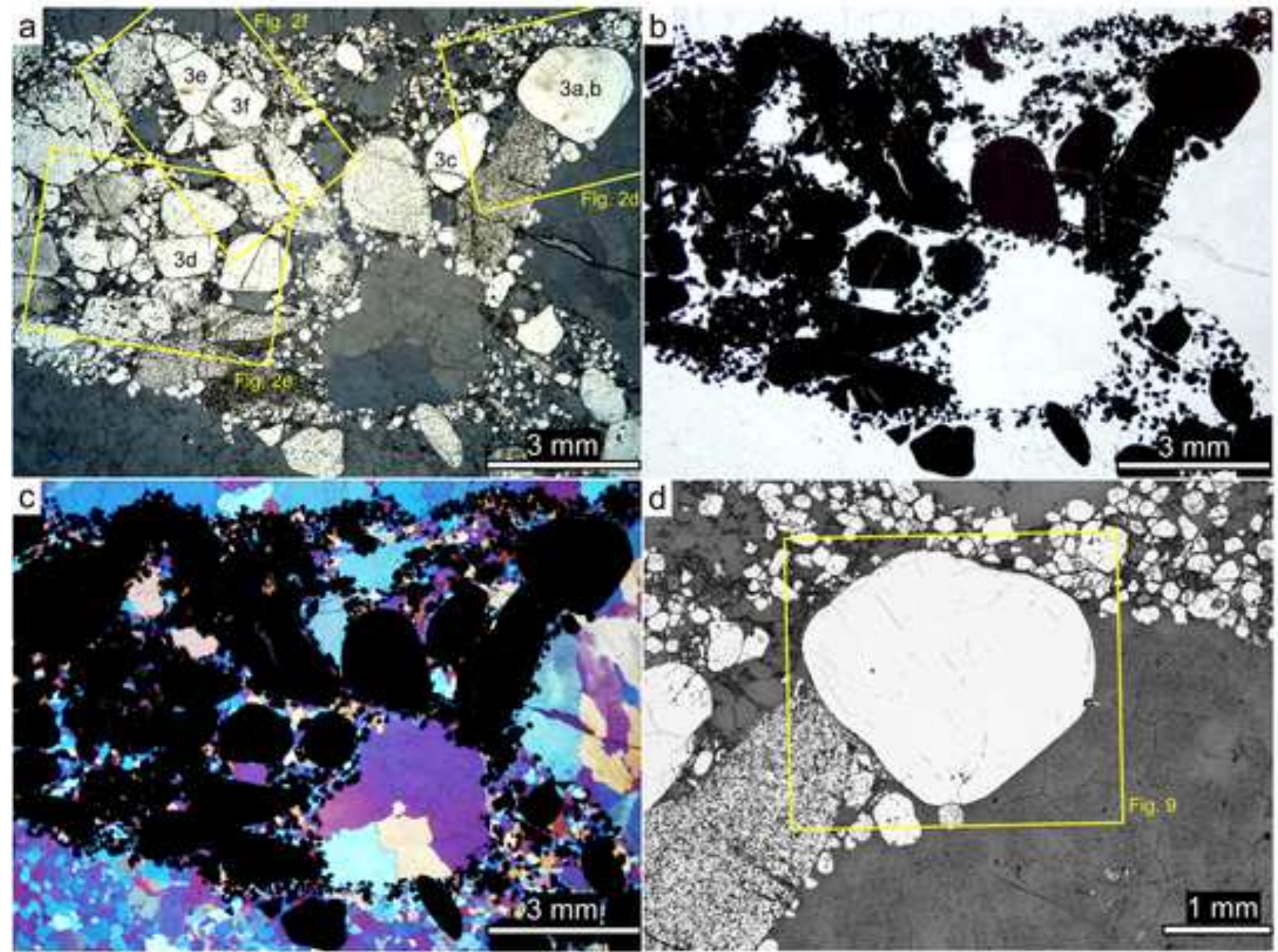

e
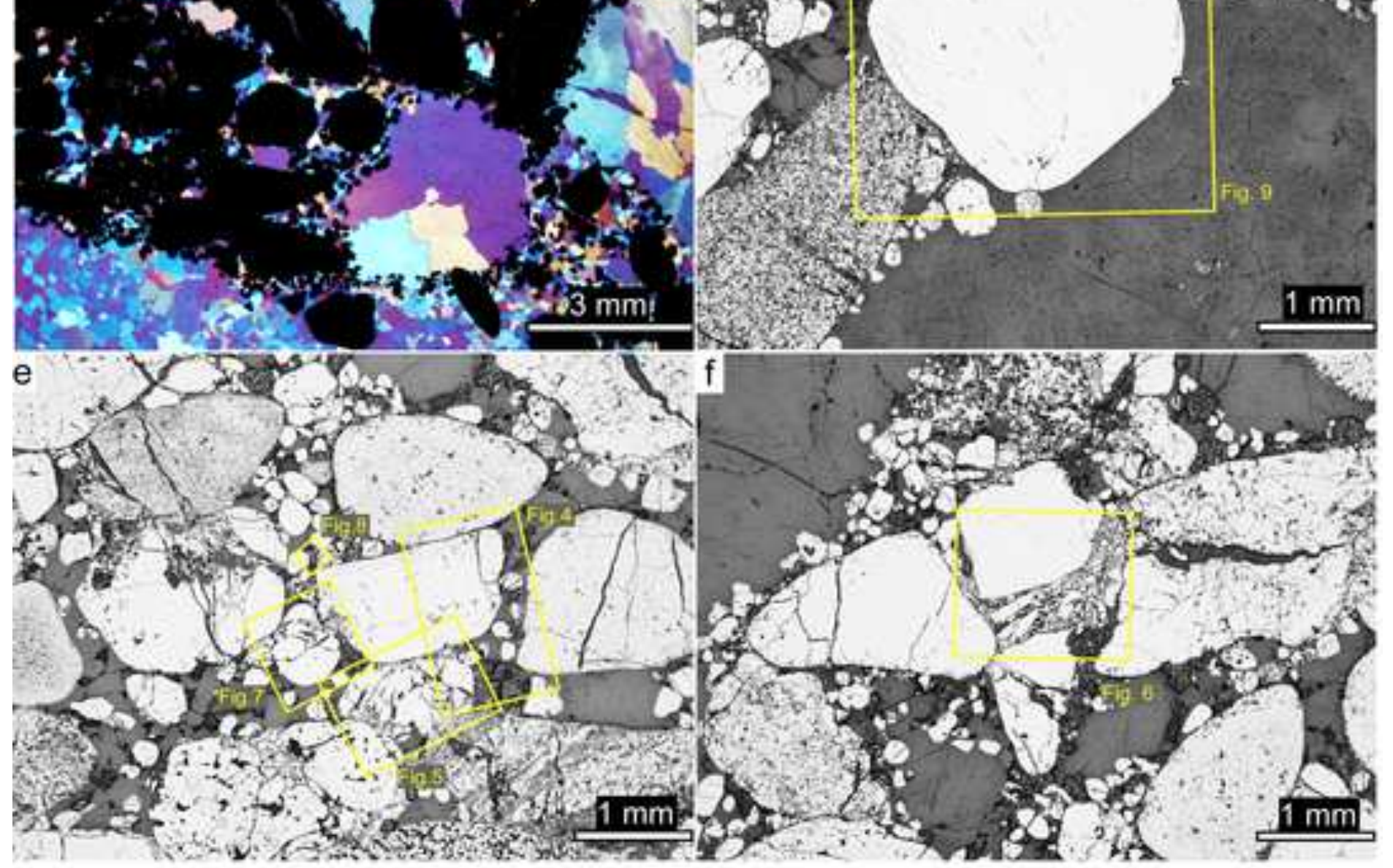

$1 \mathrm{~mm}$

Reddy \& Hough 2013. Fig. 2

recommended width $=174 \mathrm{~mm}$ 

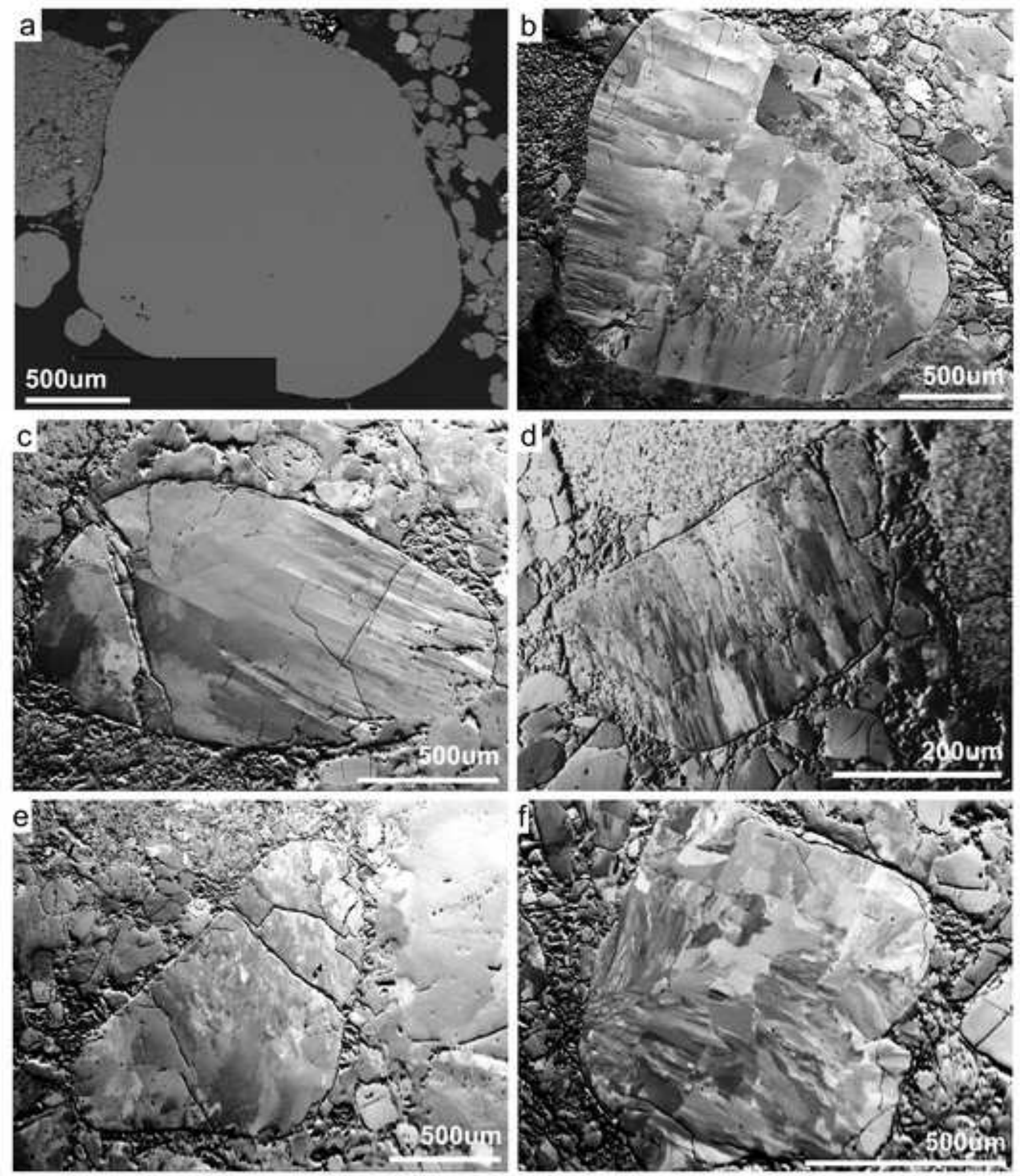

Reddy \& Hough 2013: Figure 3 


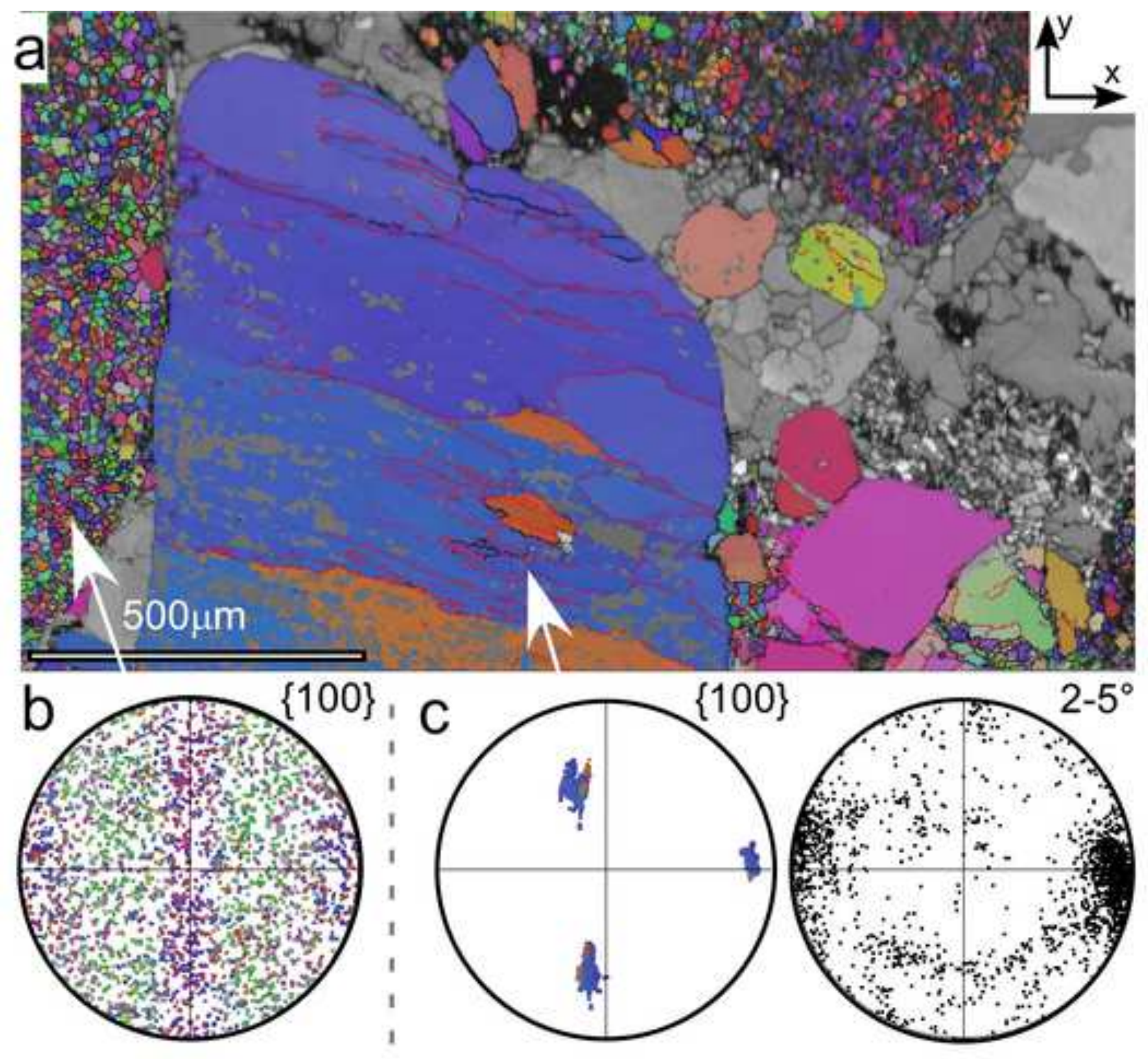

Reddy \& Hough 2013 Figure 4

Recommended width $=84 \mathrm{~mm}$ 

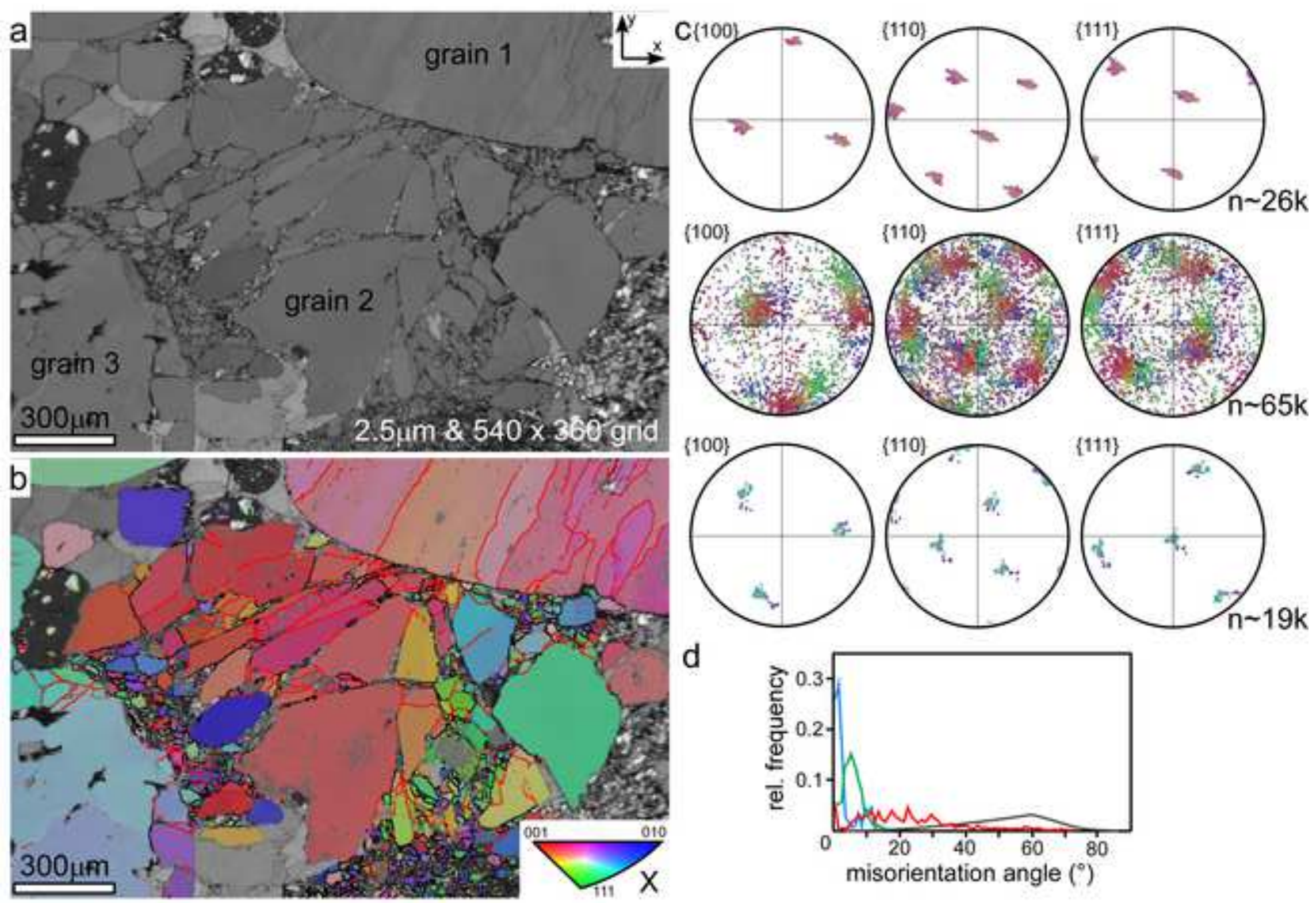

d

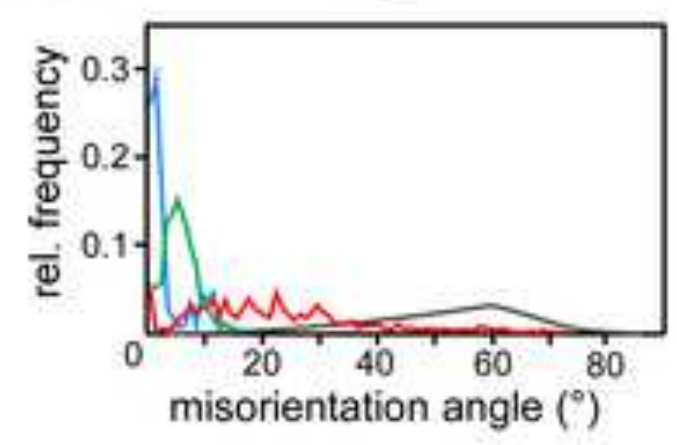

Reddy \& Hough 2013: Figure 5

Recommended Width $=174 \mathrm{~mm}$ 

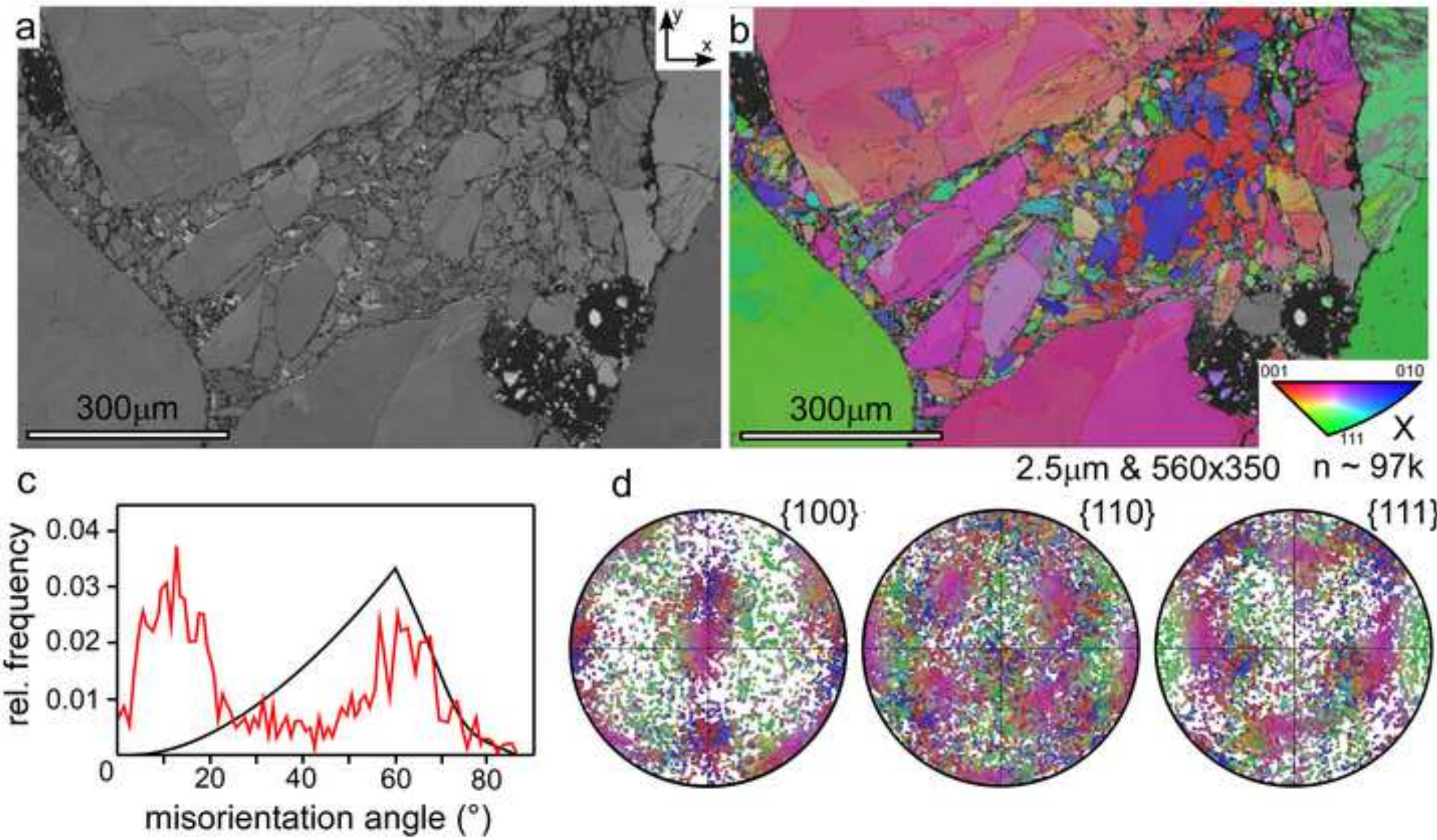

Reddy \& Hough 2013: Figure 6

Recommended width $=174 \mathrm{~mm}$ 


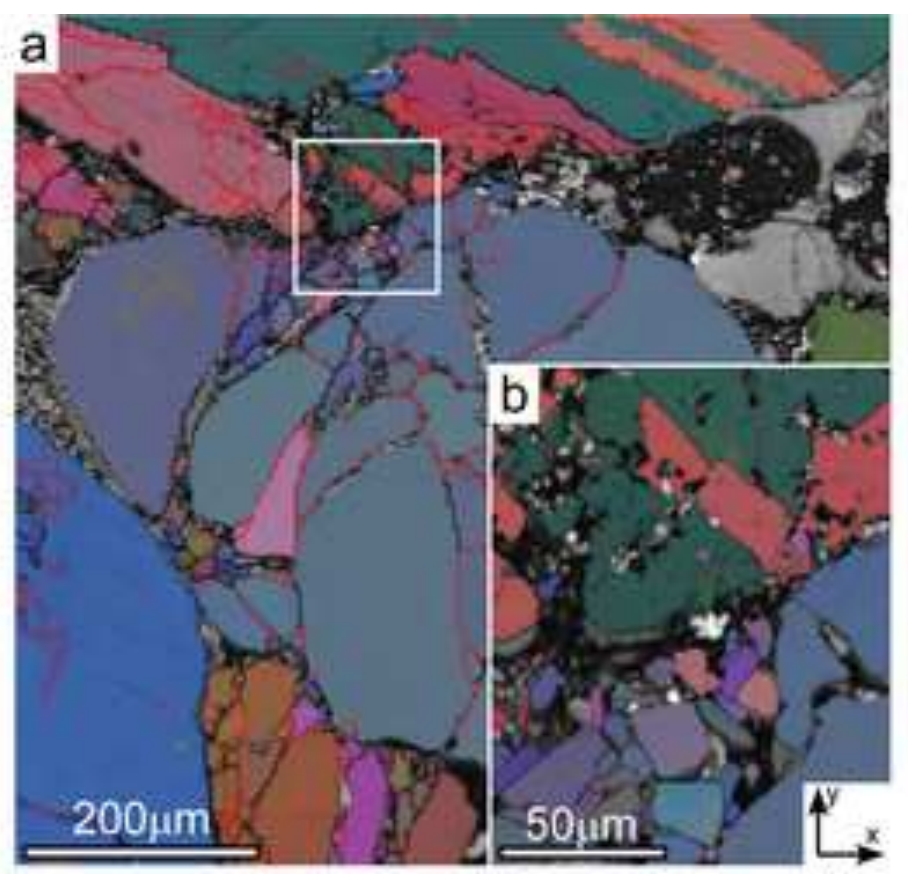

c

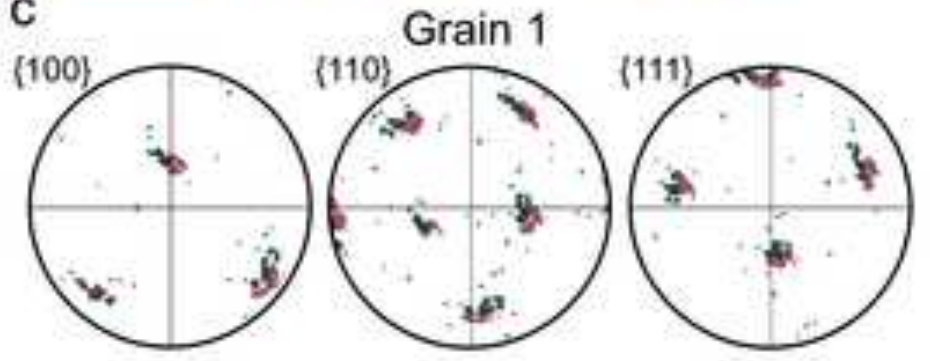

Grain 2

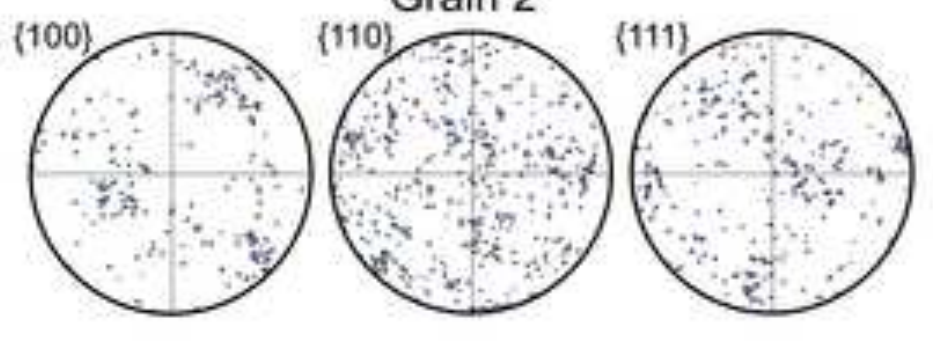

Reddy \& Hough 2013: Figure 7

Recommended width $=84 \mathrm{~mm}$ 


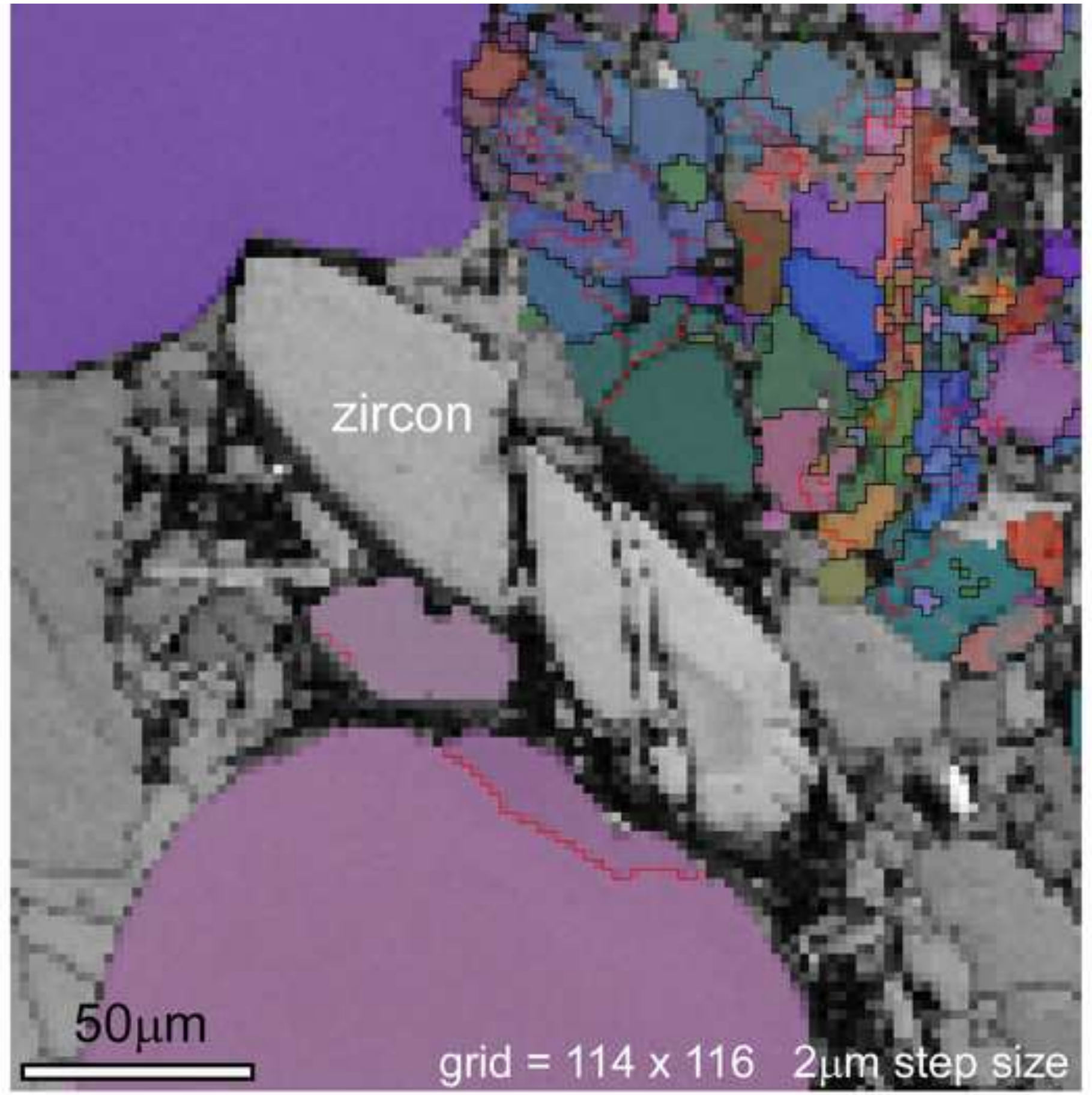

Reddy and Hough 2013. Figure 8 Recommended width $=84 \mathrm{~mm}$ 

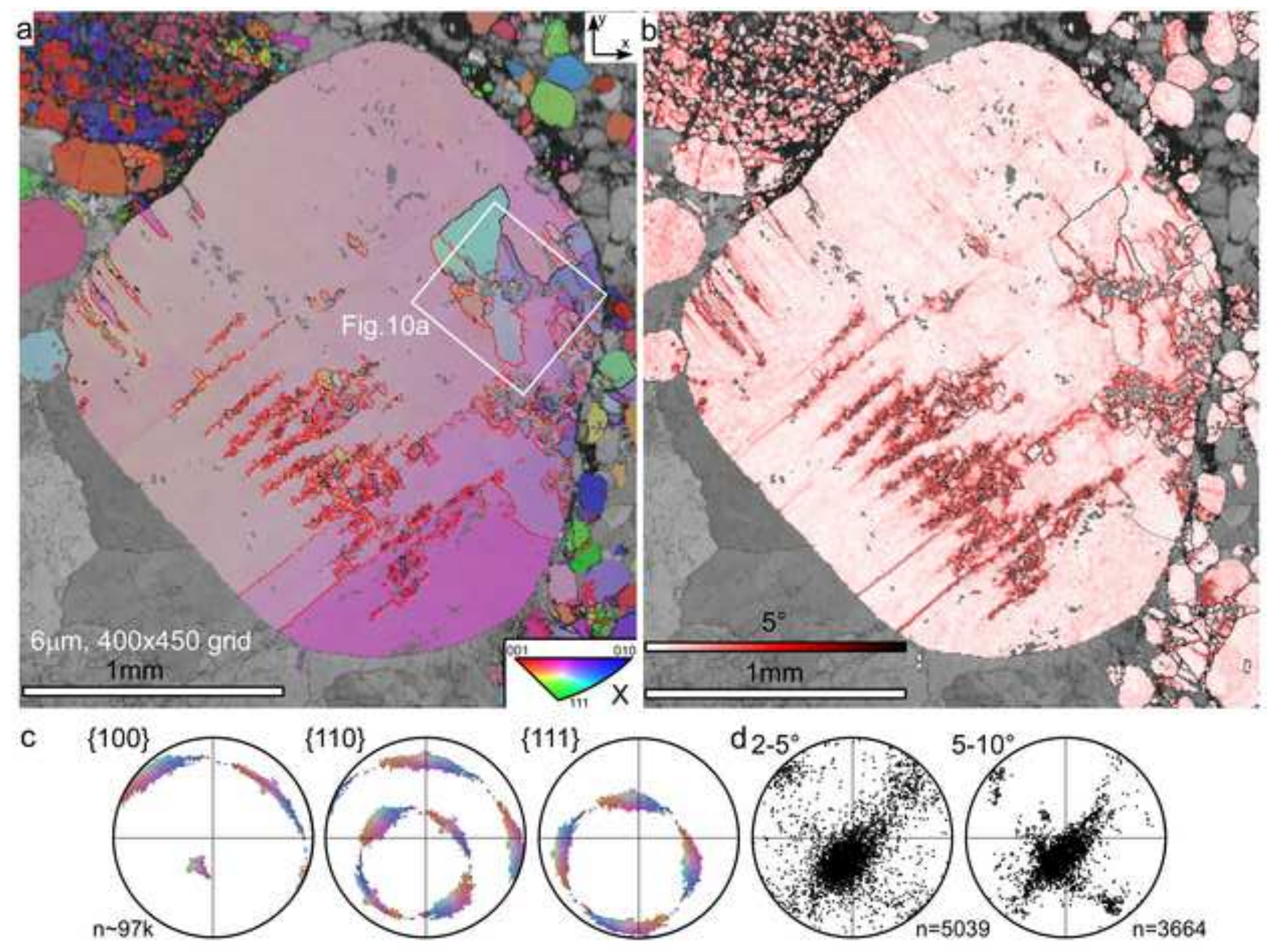

Reddy \& Hough 2012: Figure 9

Recommended width $=174 \mathrm{~mm}$ 
Click here to download high resolution image
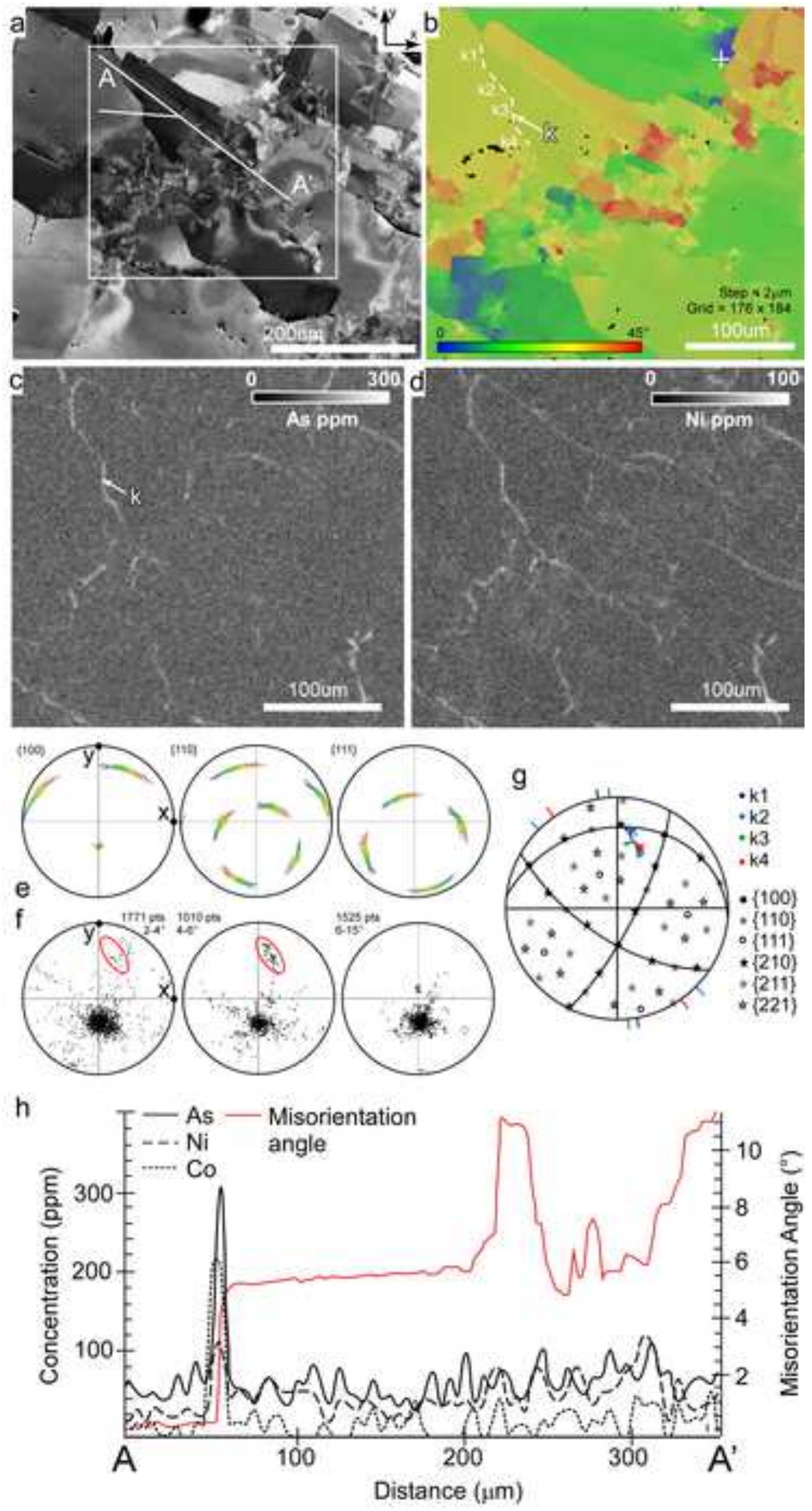

Reddy \& Hough / Figure 10 Recommended width $=174 \mathrm{~mm}$ 


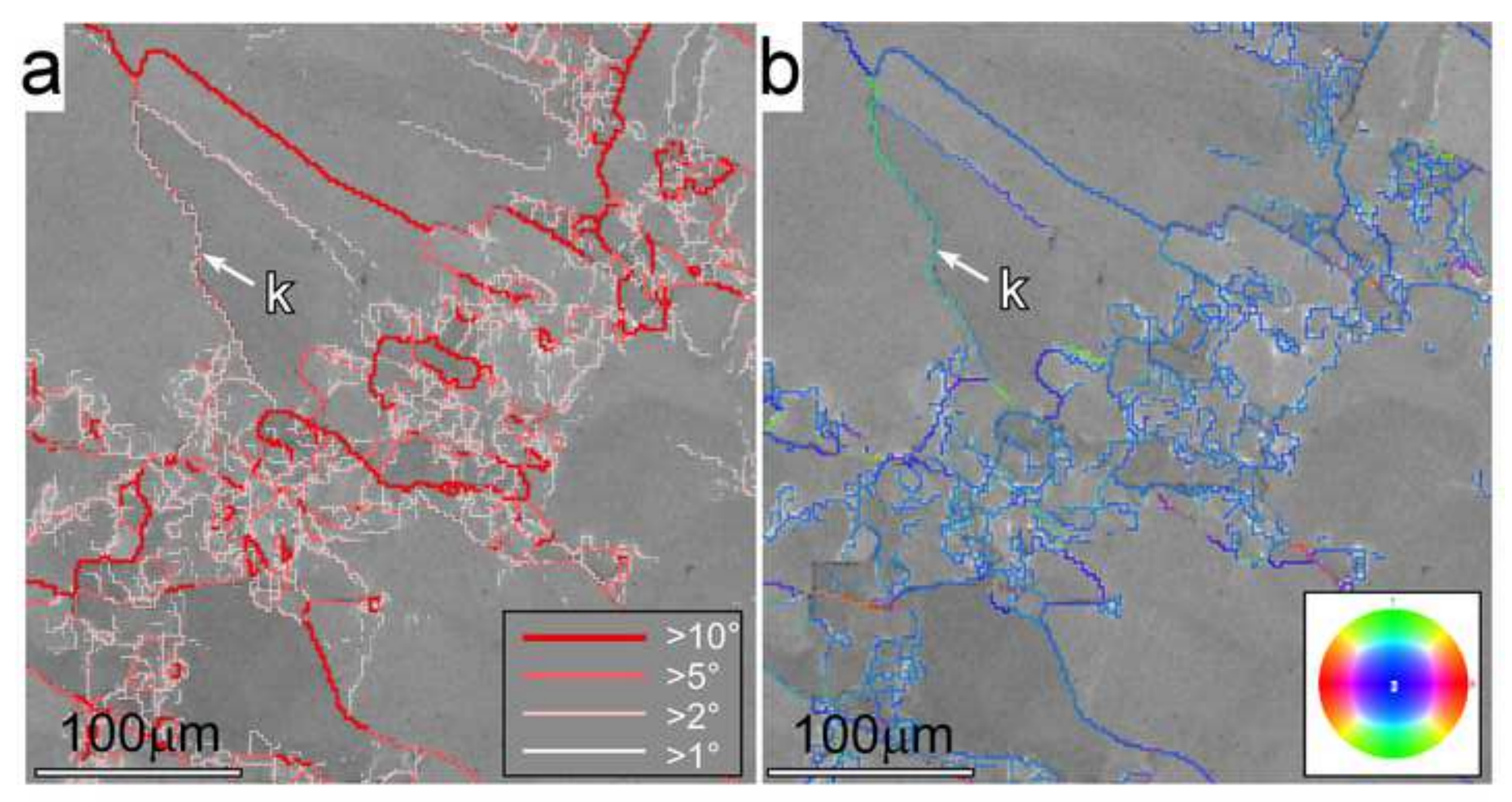

Reddy \& Hough / Figure 11
Recommended width = current size

Reddy \& Hough / Figure 11
Recommended width = current size 

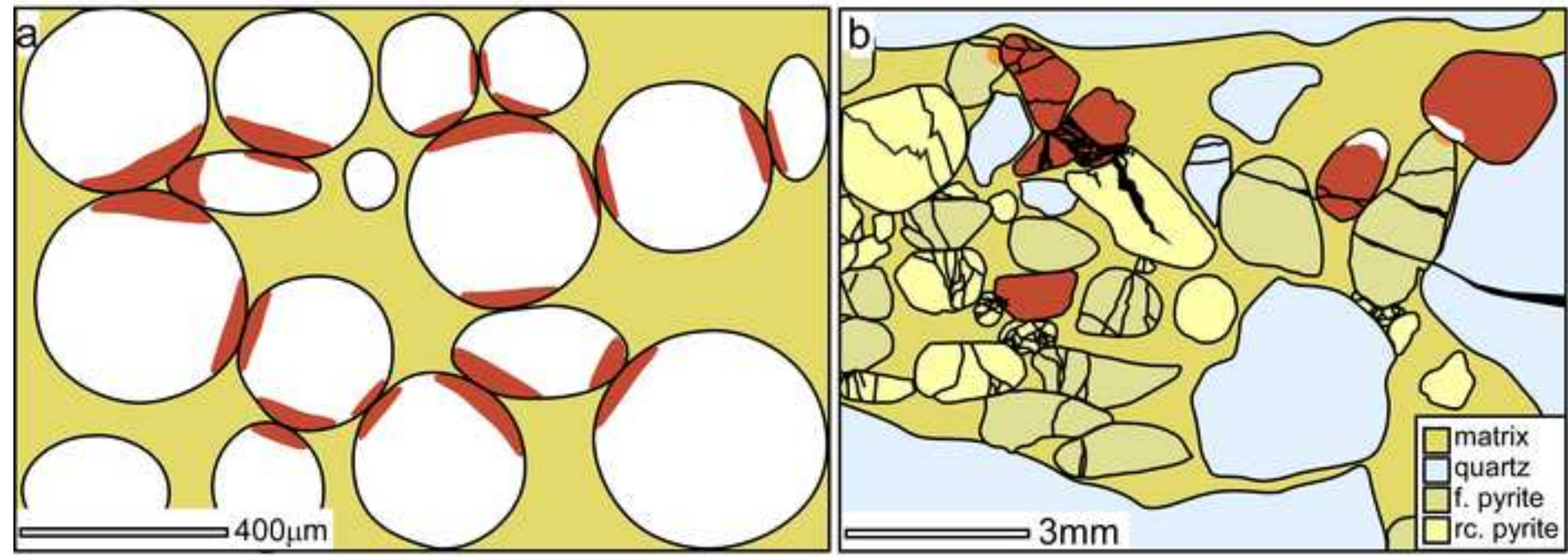

$\square$ Dislocation glide dominated

$\square$ Dislocation creep dominated (round compact pyrite)

Reddy \& Hough 2013/ Figure 12

Recommended width $=174 \mathrm{~mm}$ 